University of Rhode Island

DigitalCommons@URI

Open Access Master's Theses

1996

\title{
User Satisfaction with a Computer Based Instruction Behavior Change Intervention for Adolescent Smokers
}

Peter C. Pirillo Jr.

University of Rhode Island

Follow this and additional works at: https://digitalcommons.uri.edu/theses

\section{Recommended Citation}

Pirillo, Peter C. Jr., "User Satisfaction with a Computer Based Instruction Behavior Change Intervention for Adolescent Smokers" (1996). Open Access Master's Theses. Paper 1668.

https://digitalcommons.uri.edu/theses/1668

This Thesis is brought to you for free and open access by DigitalCommons@URI. It has been accepted for inclusion in Open Access Master's Theses by an authorized administrator of DigitalCommons@URI. For more information, please contact digitalcommons-group@uri.edu. 
USER SATISFACTION WITH A

COMPUTER BASED INSTRUCTION

BEHAVIOR CHANGE INTERVENTION

FOR ADOLESCENT SMOKERS

BY

PETER C. PIRILLO, JR.

A THESIS SUBMITTED IN PARTIAL FULFILLMENT OF THE REQUIREMENTS FOR THE DEGREE OF MASTER OF ARTS

IN

PSYCHOLOGY

$$
35 \% 3116
$$

UNIVERSITY OF RHODE ISLAND 


\begin{abstract}
This study examined user satisfaction with two computer based instruction (CBI) programs for smoking cessation, with three intervention sessions, and with several participant characteristics. Participant factors included gender, prior computer experience, stage in the behavioral change process, and reasons to smoke (Pros) and not to smoke (Cons). While the user satisfaction and computer experience data were collected for this study, the study was part of a bigger Cancer Prevention Research Consortium (CPRC) core study, which is the source of the other data. The two $\mathrm{CBI}$ smoking cessation programs were: (1) A transtheoretical model, stage of change matched, individualized, interactive program developed by the CPRC (the TTM condition); and (2) An action based, non-individualized, interactive program based on an American Lung Association model (the ALA condition). A cohort research design with delayed replication was used. Participants from four vocational high schools completed a baseline questionnaire and smokers were randomly assigned to one of the CBI conditions, which were presented serially three times, each approximately two months apart. Users were significantly more satisfied with the TTM than the ALA smoking cessation program $(p<.05)$. There was a significant relationship of user satisfaction with Pros and Cons at session 1, and with Cons over all three CBI sessions $(p<.05)$. The students' satisfaction with this TTM program, though not rated as high as possible, suggests that this stage of change $\mathrm{CBI}$ for smoking cessation should be studied within more complete multimedia presentations and over longer time. Other implications for future research are discussed.
\end{abstract}




\section{Acknowledgment}

I would like to especially thank the major professor of this thesis committee, Nelson Smith, and the Cancer Prevention Research Consortium thesis committee members, Joe Fava and Unto Pallonen, for the opportunity to work with them on this research project. They have provided me with models of how knowledgeable, insightful, helpful, and how enjoyable researchers can be. Therefore, they have also provided me with the motivation to continue working towards a research career. Fortunately, Joe Fava also provided guidance on the design and analyses of this research project. Although Nelson Smith has gone beyond what is expected from a major professor, they all have been unexpectedly understanding of my part-time university and full-time work situation.

Though I have not taken the opportunity to spend as much time with the committee member from outside the Psychology Department, Janet Hirsch, College of Nursing, it has not taken much time to know that she possesses the qualities that I value in the other committee members. I would like to thank Janet Hirsch for her support and advice.

Though not named here, the Psychology professors of the courses that I have taken which preceded this project are also greatly appreciated. They too have contributed to making this thesis possible. 


\section{TABLE OF CONTENTS}

Abstract ii

Acknowledgment iii

Table of Contents iv

Lists of Tables vi vi

Lists of Figures vii

Introduction 1

User Satisfaction $\quad 2$

Factors Related to User Satisfaction 8

$\begin{array}{ll}\text { CBI Condition } & 8\end{array}$

Stages of Change for Smoking Cessation Progress 10

$\begin{array}{ll}\text { Pros and Cons to Smoke } & 11\end{array}$

$\begin{array}{ll}\text { Gender } & 12\end{array}$

$\begin{array}{ll}\text { Computer Experience } & 12\end{array}$

$\begin{array}{ll}\text { Number of Sessions } & 13\end{array}$

$\begin{array}{ll}\text { Purpose } & 13\end{array}$

$\begin{array}{ll}\text { Hypotheses } & 15\end{array}$ 
$\begin{array}{ll}\text { Procedure } & 16\end{array}$

$\begin{array}{ll}\text { Design } & 16\end{array}$

$\begin{array}{lr}\text { Interventions } & 18\end{array}$

$\begin{array}{ll}\text { Sample } & 18\end{array}$

$\begin{array}{ll}\text { Results } & 20\end{array}$

Dependent Measure Refinement 20

Effects of Sessions, Gender, Stage of Change, and CBI Condition 22

Treatment $\times$ Stage of Change $\times$ Time ANOVA 23

Between-subject Treatment main effect 23

Treatment x Gender x Time ANOVA 29

Between-subject Treatment main effect 29

Within-subject TreatmentxGenderxTime interaction 29

Relation of PC Experience, Pros \& Cons, Satisfaction, Sessions 29

$\begin{array}{ll}\text { Discussion } & 35\end{array}$

$\begin{array}{ll}\text { Conclusion } & 39\end{array}$

$\begin{array}{ll}\text { Appendices } & 42\end{array}$

A. User Satisfaction Evaluation Screens 43

B. Baseline Questionnaire 49

C. Decisional Balance Short Form 64

D. ANOVA Summary Tables 66

$\begin{array}{ll}\text { Bibliography } & 68\end{array}$ 


\section{LIST OF TABLES}

1. Sources and Scale Items Used for the User Satisfaction Evaluation 7

2. The Cohort, Delayed Replication Research Design and Schedule 17

3. Two Component Varimax Rotated Component Pattern Solution for the User Satisfaction Evaluation

4. Design of the Treatment $\times$ Stage of Change $\times$ Time Repeated Measures ANOVA

5. Design of the Treatment $\times$ Gender $\times$ Time Repeated Measures ANOVA

6. Stepwise Multiple Regression of User Satisfaction on PC Experience and Pros and Cons of Smoking at Intervention Session 1

7. Stepwise Multiple Regression of User Satisfaction on PC Experience and Pros and Cons of Smoking at Intervention Session 2

8. Stepwise Multiple Regression of User Satisfaction on PC Experience and Pros and Cons of Smoking at Intervention Session 3 


\section{LIST OF FIGURES}

1. Mean User Satisfaction for Computer Based Instruction Treatments by the Precontemplation Stage of Change Over Time

2. Mean User Satisfaction for Computer Based Instruction Treatments

by the Contemplation Stage of Change Over Time

3. Mean User Satisfaction for Computer Based Instruction Treatments by the Preparation Stage of Change Over Time

4. Mean User Satisfaction for Computer Based Instruction Treatments

by Stage of Change at Intervention Session 1

5. Mean User Satisfaction for Computer Based Instruction Treatments

by Stage of Change at Intervention Session 2

6. Mean User Satisfaction for Computer Based Instruction Treatments

by Stage of Change at Intervention Session 3

7. Mean User Satisfaction for the Computer Based Instruction

Treatment x Females Over Time Interaction Effect

8. Mean User Satisfaction for the Computer Based Instruction 


\section{INTRODUCTION}

Computer based instruction (CBI) programs for health risk behaviors in high risk groups have the potential of offering uniformly delivered, individualized, interactive, and validated behavior change interventions. In order to contribute to remediation of the serious health problems caused by cigarette smoking, focus should be on the age group where most smokers begin smoking: adolescence (USDHHS, 1990). Furthermore, smoking rates for vocational high school students are much higher than those for their college bound peers.

The Surgeon General's 1990 report on Smoking and Health (USDHHS, 1990) presented information concerning the serious health problems from smoking which this country's adolescents face. Cigarette smoking is the most devastating preventable cause of disease and premature death in the country. The US Department of Health and Human Services (1988) has established that nicotine is a highly addictive substance and cigarette smoking is directly responsible for more than one of every six deaths in this country; that is more than 1000 deaths each day. Most smokers began smoking in their adolescent years, and earlier starters have a harder time quitting than later starters, yet research in adolescent smoking cessation is limited compared to such research for adult populations.

Improved quit rates may be accomplished if future $\mathrm{CBI}$ smoking cessation interventions are made more appealing to adolescents. If smoking addiction begins during adolescence and occurs at a higher rate for vocational students, 
then it will be important to develop CBI smoking cessation programs which will appeal to high risk vocational students.

The use of computers in schools is now common and the use of CBI for health education programs in schools is increasing. The self-help nature of CBI programs for smoking cessation offer convenience for both students and school

personnel. Yet, the effectiveness of these programs with adolescents is considered to be partially dependent on how satisfied the users are with the software (Chin, Diel, \& Norman, 1988). However, a standard evaluation for user satisfaction has yet to be developed for any type of computer software.

There is substantial need for the development of an accepted standard instrument to evaluate user satisfaction with computer based health intervention programs. This standard instrument could be used in the creation and comparison of health based software. While development of such an instrument was not the purpose of this study, the results of this study may inform future investigators with how user satisfaction scales might be better utilized.

\section{User Satisfaction}

Information on instruments to evaluate user satisfaction with computer based instruction is needed because little is known about users' satisfaction with, and attitude toward, CBI (Billings \& Cobb, 1992; Shneiderman, 1992). This study has drawn on findings from previous research on use of semantic differential instruments to measure user satisfaction (Shneiderman, 1992; Deardorff, 1986; Coleman and Williges, 1985). 
Shneiderman (1992) described five types of variables for evaluating a computer system: Time to learn, speed of performance, rate of errors by users, retention over time, and subjective satisfaction. The first four of these five factors are objective measures, the exception being subjective user satisfaction. Although a system may be evaluated highly along the other four factors, subjective satisfaction often determines the ultimate acceptance and use of any system (Chin et al., 1988). Another way to look at this is that, no matter how technically good a system is, "users are attached" (Steinberg, 1991).

Charles Osgood developed the semantic differential in the 1960's (Allen, 1986). He suggested that connotative meanings mainly follow three dimensions: evaluation (good-bad), potency (strong-weak), and activity (fast-slow). Evaluation is the primary factor, which produces about half the variance of the semantic differential scale. Important dimensions other than these three are not to be expected (Allen, 1986).

The semantic differential technique of attitude measurement is based upon consistency theories. Consistency theories view the development of attitudes as a cognitive balance between two beliefs about an object. Attitude can be described as a learned predisposition to respond in a consistently favorable or unfavorable manner with respect to a given object. Operationally, attitude toward a concept can be measured by rating the concept on a set of bipolar adjective (semantic differential) scales. An assumption of consistency theory is that people communicate their attitudes mainly with adjectives. 
Allen developed a semantic differential tool for measuring attitude toward CBI which uses 14 bipolar adjective scales. Her orientation led her to select only scales found along the evaluation dimension, yet she found three clusters of adjectives contributing to the subscales she named: comfort, creativity, and function. Allen's semantic differential tool measures overall user satisfaction and is therefore useful for various types of software. Some of Allen's semantic differential items are worded the same as those in the measures of Coleman \& Williges (1985), Deardorff (1986) and Shneiderman (1992).

Unlike Allen, Deardorff (1986) used all three of Osgood's dimensions of attitude: evaluation, potency, and activity, in his study using the semantic differential for measuring user satisfaction with a CBI system for health information. He noted that these three dimensions have been shown to be factorially stable across a wide range of studies. He reported that the semantic differential meets the requirement of concept-relevancy.

Shneiderman's (1992) Questionnaire for User Interface Satisfaction (QUIS) assesses users' attitudes and subjective satisfaction with different types of computer software. The QUIS also uses bipolar adjective (semantic differential) ratings to measure user satisfaction. Although most of the QUIS focuses on the user interface, one of the seven QUIS sections considers general user satisfaction. This general user satisfaction section of the QUIS, the Overall User Reactions section, was utilized in the present study.

Wallace, Norman, and Plaisant (1988) provided an example of use of a semantic differential, the QUIS (Shneiderman, 1992), as a primary measure of 
user satisfaction in an evaluation of a new software product. In the Overall User Reactions section of their study, participants were asked for their best reflection of their impressions about using the computer system. The overall reaction ratings indicated that users were more impressed with the system than they were satisfied with it; a classic human factors problem.

Coleman and Williges (1985), in their study of user reaction to a word processing program, used bipolar semantically anchored scales in common with those developed by Allen (1986). Coleman and Williges showed that users preferred meaningful bipolar adjective evaluation scales over open-ended questions. These semantic differential scales, along with those used by Deardorf (1986) and Shneiderman (1992) to measure user satisfaction, were included in the present study.

New interactive technologies offer opportunities to increase user satisfaction to designers of learning environments, e.g., the interactive computer based instruction environment developed for the present study. Weisberg (1992) reviewed findings that report, concomitant to productivity increases, user satisfaction increases with effective application of ergonomics in the design of visual display technologies for the workplace. The findings from ergonomics research on visual display workstations are also applicable to $\mathrm{CBI}$ learning environments.

For this study, an on-line evaluation consisting of 15 overall satisfaction questions (see Appendix A) was included at the end of each computerized intervention session. Nine questions used in the evaluation were identical to 
nine questions out of the fifteen used in Deardorff's (1986) paper and pencil semantic differential (see Table 1), and were selected based on applicability to this study. Using a 5-point Likert style scale, participants chose the numbers that best matched their opinion about the session.

Additional questions which measured overall satisfaction with the evaluation, and which applied to this study, included four by Shneiderman (1992) and two by Coleman and Williges (1985), as shown in Table 1. For conceptual rather than visual order, Table 1 is arranged with similar questions aligned horizontally. The four questions by Shneiderman, which where used in the present interventions, came from the Overall User Reactions section of the QUIS (Shneiderman, 1992). These four questions assessed four factors of overall subjective reactions of users to the computer system. The results from these questions provided ratings which can characterize an overall profile of $\mathrm{CBI}$ systems. The use of only these four questions is supported by Shneiderman's (1992) statement that the QUIS may be modified to meet a particular research need. Shneiderman elaborated that items specific to the domain of the research project may be added, but the items should be phrased in a similar way, with meaningful end anchors for the Likert scales.

Table 1 shows that two of the Coleman and Williges (1985) items were used in this study. Coleman and Williges (1985) used these two bipolar semantically anchored items to ask users to describe their reactions to using a word processor. These two semantic differential items are applicable to the present exploratory study and are similar to items in the Deardorff (1986) and Shneiderman (1992) 


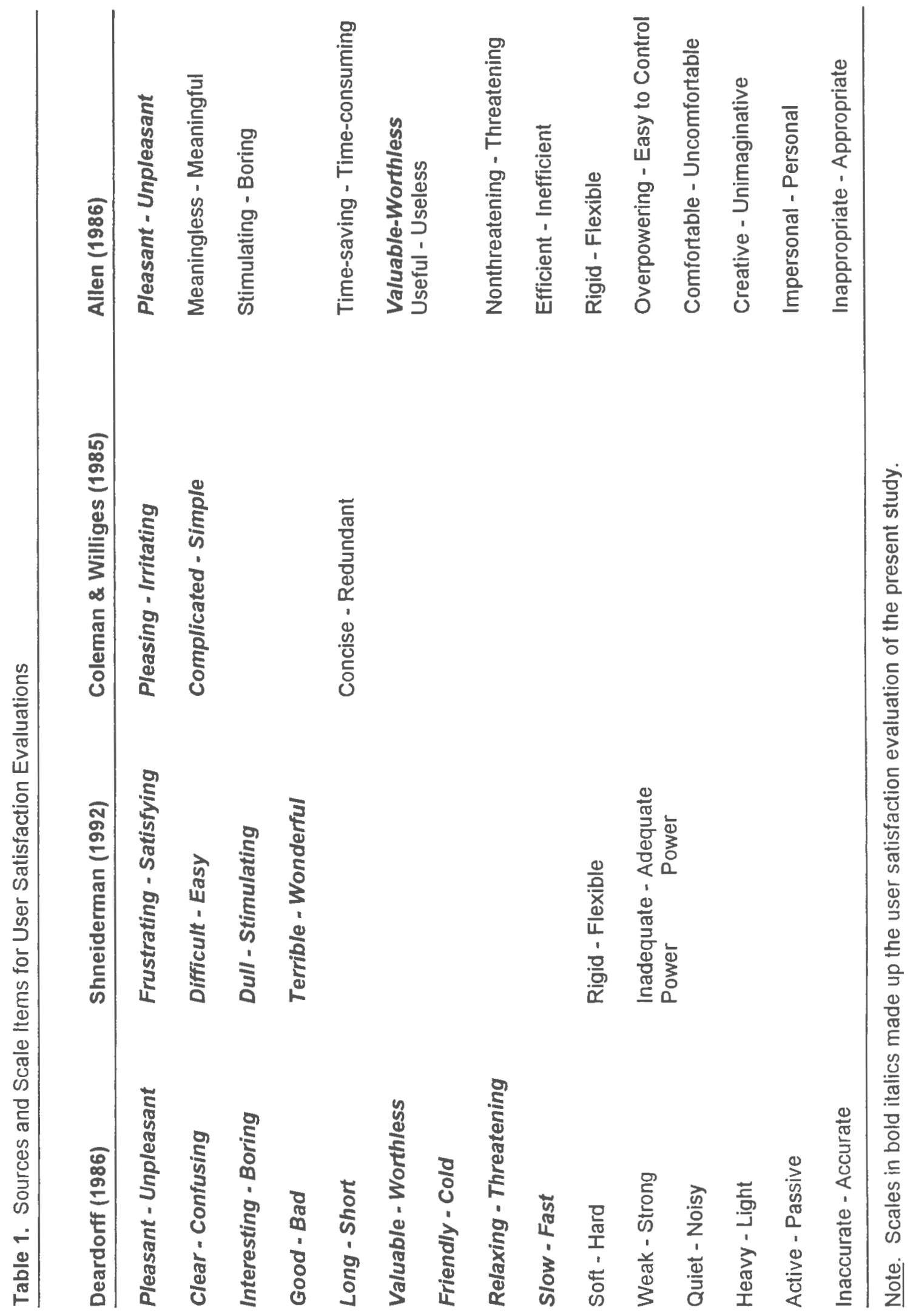


studies. Given that the evaluation occurred after a long evaluation for the core study, the present study minimized time to complete the user satisfaction evaluation with a limit of 15 items, equal to the number of items in the Deardorff (1986) study.

Allen's (1986) development of a semantic differential for CBI used 14 items to measure user satisfaction with CBI. Her study was not located and thus not considered before the present study was conducted. Yet Table 1 shows that two of the 15 items used in the present study, Pleasant-Unpleasant and ValuableWorthless, are identical to those used by Allen (1986). Three other items used in the present study are similar to those used by Allen (1986).

\section{Factors Related to User Satisfaction}

\section{CBI Condition}

The Kulik and Kulik (1991) meta-analysis presented findings from 254 controlled $\mathrm{CBI}$ evaluation studies. Out of the 254 studies included in their metaanalysis, only 22 studies included attitude evaluations. Kulik and Kulik reported that 16 of 22 studies found more positive attitudes toward quality of instruction in $\mathrm{CBI}$ classes than in conventionally taught classes; four studies showed more negative attitudes; and two studies showed no significant difference; however, they did not report which ones these 22 studies were and these have not been located. They also did not report if the 22 studies that included these attitude measures used semantic differential scales. 
Steinberg's (1991) review of CBI research found that media comparison studies (e.g., CBI compared to teacher instruction) report positive user attitudes toward $\mathrm{CBI}$ and reduced learning times. However, she proposed that comparison studies may compare, rather than the media, the instructional material presented by the media. If she is correct, such studies would not document clearly that the superiority of learning is due to characteristics unique to $\mathrm{CBI}$. Extending her thinking, such studies may likewise not document clearly that positive user attitudes toward $\mathrm{CBI}$ are due to characteristics unique to $\mathrm{CBI}$.

Deardorff (1986) studied computerized health education compared to face-to-face and written formats. He found that the face-to-face and computer conditions were assessed in positive terms, but that the written format was assessed more negatively.

The QUIS has been used to provide ratings which can characterize the overall profile of a system and can detect differences between competing systems. For example, the QUIS was used to compare two Pascal programming environments and indicate which one was preferred by the participants (Chin et al., 1988).

Psychology is one of the multiple disciplines / sciences that is particularly involved in the "psychosocial stresses" research area of ergonomics (Weisberg, 1988). Weisberg reviewed ergonomics research on interactive learning technologies (e.g., CBI and expert systems) and presented guidelines to balance human performance, learner satisfaction, and well-being. To briefly summarize Weisberg's (1988) findings, he proposed an ergonomic model for the learnplace 
by delineating the relationships among: (a) the learner; (b) the interactive technologies; (c) the workstation and environment; and (d) the learning / performance context. Weisberg reviewed effective ergonomic interventions which suggest significant health and productivity gains, in the range of 20 percent, which may apply to an interactive learning environment such as the $\mathrm{CBI}$ intervention used in the present study.

In the present study, participants were grouped to receive one of the two intervention conditions. Black and white prints of typical color screens for the TTM condition satisfaction evaluation of the present study are at the end of Appendix A.

\section{Stages of Change for Smoking Cessation Progress}

For this study, participants were assessed as being at one of three stages of change at their first $\mathrm{CB}$ I intervention session. This grouping was based on the stages of change Health Questionnaire (Appendix B) developed to assess participants' commitment to change their problem behavior (McConnaughy, DiClemente, Prochaska, \& Velicer, 1989; McConnaughy, Prochaska, \& Velicer, 1983). While there are five stages of change for smoking cessation, there are three discrete mutually exclusive early stages of change that represent the current smokers assessed in this study, namely: Precontemplation, Contemplation, and Preparation. Precontemplation is defined as currently engaging in a problem behavior and having no plans to change the problem behavior in the next six months. Contemplation is defined as planning to cease 
the problem behavior in the next six months. Preparation is defined as planning to cease the problem behavior in the next thirty days and having attempted to do so in the past twelve months. Two later stages of change represent former smokers who have been continuously quit for less than six months (Action) or greater than six months (Maintenance).

This study was the first to investigate how stages of change for smoking cessation progress is related to user satisfaction with a CBI intervention, therefore no literature was available for review. Yet, literature was available that may apply to the effect of stage progress on user satisfaction. Billings and Cobb (1992) found that the strongest predictor of learner achievement was attitude (comfort) toward computer assisted instruction.

\section{Pros and Cons of Smoking}

This study was also the first to investigate how decisional balance is related to user satisfaction with a $\mathrm{CBI}$ based intervention, therefore no literature was available for review. In this study, a twelve-item short form of the Decisional Balance Inventory (Velicer et al., 1985) was developed to assess the Pros and Cons of smoking (see Appendix C). The inventory was originally constructed with 24 items to measure the cognitive and motivational aspects of human decision making as it applied to smoking. Participants rated each item on a 5point Likert scale ranging from (1) not important to (5) extremely important. Six items represented pros of smoking and six items represented cons of smoking. The relative strength of the pros and cons is highly related to movement through 
the stages of change of the Transtheoretical Model. The two decisional balance subscales were presented to all of the participants during the $\mathrm{CBI}$ intervention sessions.

\section{Gender}

Deardorf's (1986) comparison study of computerized health education found that females rated three scales significantly more satisfactorily than did males. However, no gender differences were found on seven of the semantic differential scales used to assess the intervention formats. For this study, information on gender was obtained from the paper and pencil baseline survey prior to the first $\mathrm{CBI}$ intervention.

\section{Computer Experience}

Deardorff's (1986) comparison study of computerized health education programs found no differences between high and low computer experience subgroups of the computer condition. Yet, high computer experience was correlated with the program being rated as boring. In the Wallace et al. (1988) study, previous computer experience with a variety of technical interfaces had no significant effect on user satisfaction ratings.

For the present study, computer experience was assessed by one question (see Appendix A, question 19), using a 5-point Likert scale. Prior computer experience was assessed during the first $\mathrm{CBI}$ intervention. Similar to 
the Deardorff (1986) study, all of the current participants self-rated their computer experience.

\section{Number of Sessions}

Chin, Norman, and Shneiderman (1987) found that, for both an interactive environment on a PC and a batch run environment on a mainframe computer, user satisfaction increased with time, i.e., over intervention sessions. This is one of the studies that was used to develop the current QUIS (Shneiderman, 1992). In the present study, the CBI interventions were repeated over three sessions for longitudinal analyses of the above factors related to user satisfaction.

\section{Purpose}

The purpose of this study was to examine user satisfaction with two different computer based instruction (CBI) programs for smoking cessation, with three intervention sessions, and with several participant characteristics. These participant factors included gender, computer experience, stage of change (Prochaska \& DiClemente, 1984), and reasons to smoke (Pros) and not to smoke (Cons) (Velicer, DiClemente, Prochaska, \& Brandenbury, 1985). The two CBI smoking cessation programs were: (1) A transtheoretical model, stage of change matched, individualized, interactive program (the TTM condition); and

(2) An action based, non-individualized, interactive intervention based on an American Lung Association model (the ALA condition). 
While user satisfaction and computer experience data were collected for this thesis, the study was part of a bigger study, which was the source of the other data. The bigger study was conducted at the URI Cancer Prevention Research Center (CPRC) and is referred to as the core study (P.I., J.O. Prochaska) in this thesis.

The present study sought information that could suggest ways to predict and improve user satisfaction with the $\mathrm{CBI}$ interventions. To do this, the study examined factors posited to relate to user satisfaction with the interventions delivered in the bigger core study.

Based on the Transtheoretical Model for Smoking Cessation (Prochaska \& Diclemente, 1984) as applied in the CBI expert system (Velicer, Prochaska, Bellis, DiClemente, Rossi, Fava, \& Steiger, 1993), the effects of initial stage of change for smoking cessation on user satisfaction were examined in the present study. The relationships between user satisfaction and the Pros and Cons of smoking, as measured by subscales of the Decisional Balance Inventory (Velicer, et al., 1985), were also studied. The effects of gender and prior computer experience were examined for their relationship to user satisfaction.

The ALA program provided an action oriented intervention. It assumed (as do most current smoking cessation programs) that the participant is prepared to take immediate action to quit, or is in the Preparation stage, as viewed in the Transtheoretical Model (Prochaska \& Diclemente, 1984). Though the ALA program was not individualized, it was considered interactive in that it provided health information with fixed suggestions for smoking cessation and the 
participant responded to evaluative questions. Unlike the ALA intervention, the TTM intervention was individualized and interactive according to the working technical definition of the MIT Media Lab: "Mutual and simultaneous activity on the part of both participants..." (Brand, 1992).

\section{Hypotheses}

This study was an exploratory investigation of factors related to user satisfaction with computer based instruction ( $\mathrm{CBI}$ ) smoking cessation interventions for adolescent smokers. The following six hypotheses were made for the six factors included in this study. First, for $\mathrm{CBI}$, satisfaction ratings will significantly differ for the TTM and ALA conditions. Second, for stages of change for smoking cessation progress, satisfaction will significantly differ across the stages of change. Third, for decisional balance, reasons to smoke (Pros) and not to smoke (Cons) will significantly relate to user satisfaction ratings. Forth, for gender, males will have significantly different user satisfaction than females. Fifth, for computer experience, prior computer experience will significantly relate to user satisfaction ratings. Sixth, for number of sessions, user satisfaction will significantly vary across the number of sessions. Because little literature was found to apply for some of the factors of this study, some hypotheses reflect consensus rather than past findings. 


\section{METHOD}

\section{Procedure}

Analyses were conducted on data from the core study, which included the user satisfaction data collected specifically for the present study. The core study was designed to evaluate the effectiveness of a computer based intervention to promote smoking cessation in adolescents. It was funded by a 1992 American Cancer Society research grant and focused on smoking cessation in vocational students from four high schools. Professor James O. Prochaska, URI Department of Psychology, CPRC, was the Principal Investigator for the grant titled: Smoking Cessation for Vocational Students by Computer-Assisted Instruction. The grant provided the computers, software, and programmers for the CBI systems.

Permission was obtained from the American Lung Association to modify the Tobacco Free Teens program for use in the core study. Although originally designed as a clinic based cessation program, it was modified for administration by computer based instruction (CBI) for this study.

\section{Design}

This study used a cohort research design, which incorporated a delayed replication (See Table 2), in order to provide for maximum use of resources. The $\mathrm{CBI}$ interventions with the user evaluation questions were started in the fall semester, 1992 and were presented serially three times, approximately two 
months apart. The project lasted 12 months and the last CBI intervention session was delivered in June, 1993.

Table 2. The Cohort, Delayed Replication Research Design and Schedule

Time in Months

\begin{tabular}{lllllllllll}
0 & 1 & 2 & 3 & 4 & 5 & 6 & 7 & 8 & 9 & 10 \\
\hline
\end{tabular}

School 1

$\mathrm{O}_{0}$

$\begin{array}{lcl} & \text { Year } 1 & \\ l_{1} & l_{2} & l_{3}\end{array}$

School 2

$\mathrm{O}_{0}$

$l_{1}$

$\mathrm{I}_{2}$

$l_{3}$

School 3

$\mathrm{O}_{0} \quad \mathrm{l}_{1}$

$I_{2}$

$l_{3}$

School 4

$\mathrm{O}_{0}$

Year 2

Note. $I_{1,2,3}=$ Three CBI intervention sessions; $\mathrm{O}_{0}=$ Baseline questions.

Each of the vocational school students who volunteered to participate were presented a paper and pencil baseline survey about two months prior to the first intervention session. The survey assessed demographics and smoking history questions for the core study. During the first of three $\mathrm{CBI}$ intervention sessions, the smokers were randomly assigned to the TTM or ALA condition. Overall user satisfaction ratings indicated which $\mathrm{CBI}$ condition was more satisfactory to adolescent smokers. 


\section{Interventions}

Each $\mathrm{CBI}$ intervention was delivered at each school in approximately 7-10 days using IBM compatible personal computers with 14 inch monitors. The intervention sessions were self-paced, lasting approximately 15 minutes. Up to seven participants received the $\mathrm{CBI}$ intervention at one time, each working at individual computers. At the end of each of the ALA and TTM CBI interventions, the system interactively presented user evaluation questions and recorded participant responses.

A research staff member of the CPRC assisted participants with the use of the individually delivered CBI programs, including instruction on use of a mouse as necessary. Both $\mathrm{CBI}$ conditions used a mouse as the sole input device and assumed no prior knowledge of computers. Participants needed only to click on their selection from a 5-point Likert scale for each of the evaluation questions. A typical screen with a question and the response scale is shown at the end of Appendix A.

\section{Sample}

For the baseline survey of the core study, the sample consisted of all selfidentified smokers and non-smokers who agreed to participate in the smoking cessation study. These participants made up nearly $80 \%$ of the students from four Rhode Island vocational-technical high schools. For the scope of this thesis, which analyzed data for the smokers only, the sample consisted of all 
self-identified smokers. Smokers consisted of approximately $30 \%$ of the vocational school student population.

From self report during the baseline survey, 185 smokers were identified out of all the students in the tenth and eleventh grades of the four vocational schools. The baseline survey of the sample showed that $88 \%(n=163)$ of the smokers were Caucasian and the remaining $12 \%(n=22)$ were of other race categories, with no one category representing more than $3 \%(n=6)$ of the participants.

After the baseline survey, the number of participating smokers decreased in each subsequent intervention session due to attrition. At Intervention Session 1,164 smokers participated in the $\mathrm{CBI}$ user satisfaction evaluation. At Intervention Session 2, 119 smokers participated, and at Intervention Session 3, 110 smokers participated in the CBI user satisfaction evaluation.

At the first intervention session, the following descriptions applied. For stage of change, $44 \%(n=72)$ of the smokers were in the Precontemplation stage, $29 \%(n=47)$ in the Contemplation stage, and $27 \%(n=45)$ in the Preparation stage of change. The sample also showed that $51 \%(n=84)$ of the smokers were female and $49 \%(n=80)$ were male. Also at Intervention Session $1,61 \%(n=100)$ of the smokers were in the TTM condition and $39 \%(n=64)$ of the smokers were in the ALA condition. 


\section{RESULTS}

\section{Dependent Measure Refinement}

A Principal Components Analysis (PCA) was performed to test for a meaningful structure of latent factors to reduce the data from the 15 overall satisfaction items to meaningful subscales, each with several items. Such subscales of overall user satisfaction would increase the reliability of the measures for the analyses of variance which examined these measures as dependent variables. It was assumed that more than one subscale would result from the PCA, based on Osgood's hypothesized dimensions of semantic differential (evaluation, potency, and activity) as noted by Allen (1986).

A Principal components analysis (PCA) with a Varimax rotation (Kaiser, 1958) was performed as an exploratory statistical procedure to examine the overall user satisfaction items. Data from the first evaluation session performed at the end of the first intervention session was used for this analysis. Listwise deletion of items was used to form the correlation matrix for analysis and resulted in an effective sample size of 164 . Item analyses were conducted and a measure of internal consistency, coefficient alpha (Cronbach, 1951), was also calculated.

The best solution for the PCA was a two component solution, based on a convergence of the MAP rule (Velicer, 1976), a parallel analysis approximation (Allen \& Hubbard, 1984), and the Scree Test (Cattell, 1966). The two components represented $54.3 \%$ of the variance. Table 3 presents the user 
satisfaction evaluation items in the order they were presented to participants, at the end of each intervention session. An examination of the resulting component pattern and the item loadings (See Table 3) suggested 10 of the original 15 items loaded highly on the Component I (evaluative) scale and the remaining five items loaded on the Component II (activity-potency) scale.

Table 3. Two Component Varimax Rotated Component Pattern Solution for the User Satisfaction Evaluation Scale

\begin{tabular}{lllll}
\multicolumn{2}{l}{ User Satisfaction Evaluation Items } & \multicolumn{2}{c}{ Component } \\
\cline { 4 - 5 } & & I & II \\
\hline 1. & Unpleasant & Pleasant & $\mathbf{0 . 6 3}$ & 0.13 \\
2. & Short & Long & 0.01 & $\mathbf{0 . 6 6}$ \\
3. & Bad & Good & $\mathbf{0 . 7 9}$ & 0.12 \\
4. & Cold & Friendly & $\mathbf{0 . 6 8}$ & 0.16 \\
5. & Worthless & Valuable & $\mathbf{0 . 8 0}$ & 0.11 \\
6. & Boring & Interesting & $\mathbf{0 . 8 7}$ & 0.03 \\
7. & Threatening & Relaxing & $\mathbf{0 . 7 4}$ & 0.001 \\
8. & Fast & Slow & 0.24 & $\mathbf{0 . 5 5}$ \\
9. & Confusing & Clear & 0.29 & $\mathbf{0 . 5 5}$ \\
10. & Wonderful & Terrible & $\mathbf{0 . 6 2}$ & 0.01 \\
11. Satisfying & Frustrating & $\mathbf{0 . 7 7}$ & 0.20 \\
12. & Stimulating & Dull & $\mathbf{0 . 7 9}$ & 0.07 \\
13. & Easy & Difficult & 0.15 & $\mathbf{0 . 7 0}$ \\
14. & Pleasing & Irritating & $\mathbf{0 . 8 0}$ & 0.24 \\
15. & Simple & Complicated & 0.23 & $\mathbf{0 . 7 3}$
\end{tabular}

Note. Bold italics indicate the component that items load on.

Component $I$ is a 10 item evaluative scale.

Component II is a 5 item activity-potency scale.

The coefficient Alpha or internal consistency (Cronbach, 1951) was very high (0.92) for the 10 item scale and was low (0.64) for the five item scale. Nunnally (1978) suggests 0.70 as a lower acceptable bound for alpha, while 
DeVellis (1991) considers values of alpha below 0.65 as undesirable for research scales. Because of the low internal consistency for the five item activity-potency scale, only the 10 item evaluative scale was used for the remaining analyses of this study.

The item loadings of the activity-potency scale (See Table 3) indicate that the scale is a potentially strong one because they are either high or low. Therefore, it appears that more items would load on the activity-potency scale with high internal consistency, making it a useful scale, had a larger number of potential items for this scale been included in the study.

\section{Effects of CBI Condition, Stage of Change, Gender, \& Sessions}

Because multiple dependent measures had been expected to result from the PCA performed on the 15 items, a four-way repeated measures multivariate analysis of variance (MANOVA : $2 \times 3 \times 2 \times 3$, Treatment $x$ Stage of Change $x$ Gender $x$ Session), was originally proposed to test for effects on user satisfaction. The levels of the four factors were respectively, the two CBI conditions (TTM and ALA), three stages of change (Precontemplation, Contemplation, and Preparation), the male and female attributes, and the three serially presented intervention sessions that provided for the longitudinal analyses. Participants were assigned to their appropriate stage of change at the first intervention and this assessment defined the levels of the stage grouping variable over the three interventions sessions. 
Because only the 10 item evaluative scale was used, a four-way repeated measures ANOVA rather than the proposed four-way repeated measures MANOVA was applicable. However, the number of subjects in some cells was too small to produce reliable results using the four-way repeated measures ANOVA. Consequently, a revised design used two three-way repeated measures ANOVAs with adequate cell size.

Since the Stage $x$ Treatment and Gender $x$ Treatment interactions were both judged important to examine, the two three-way repeated measures ANOVAs performed were, 1) Treatment $\times$ Stage of Change $\times$ Time, and 2) Treatment $x$ Gender $x$ Time. The designs of these two repeated measures factorial ANOVAs are shown in Tables 4 and 5.

\section{Treatment $\times$ Stage of Change $\times$ Time Repeated Measures ANOVA \\ Between-subject Treatment main effect}

There was a marginally significant Treatment effect $(F(1,93)=3.84$, $p=.053)$. User satisfaction was more positive for the TTM $(N=62, \underline{M}=3.55$, $\underline{\mathrm{SD}}=0.78)$ than $\mathrm{ALA}(\mathrm{N}=37, \underline{M}=3.24, \underline{\mathrm{SD}}=0.91)$ intervention, based on the evaluation scale. An ANOVA summary table is located in Table D-1 of Appendix D. There were no other significant effects, but the Treatment $\times$ Stage of Change interaction was close to significant $(F(2,93)=2.70, p=.073)$. Figures $1-6$ examine this near significant interaction. 
Table 4. Design of the Treatment $x$ Stage of Change $x$ Time Repeated Measures ANOVA

Treatment

Condition

TTM
Stage of

Change

PC

C

PR

PC

C

PR

$\begin{array}{lll}\underline{!}_{1} & \underline{\bigsqcup}_{2} & \underline{I}_{3}\end{array}$

$x \quad x$

$x \quad x \quad x$

$x \quad x \quad x$

ALA

Note. $\mathrm{PC}=$ Precontemplation, $\mathrm{C}=$ Contemplation, $\mathrm{PR}=$ Preparation.

$I_{1,2,3}=$ Three $C B I$ interventions and assessments.

${ }^{a}$ All participants received treatments at all of the intervention sessions.

Table 5. Design of the Treatment $\times$ Gender $\times$ Time Repeated Measures ANOVA

Treatment

Condition

TTM

ALA
Gender

Female

Male

Female

Male

Sessions
$\begin{array}{ccc}\underline{I}_{1} & \underline{l}_{2} & \underline{l}_{3} \\ \mathrm{X} & \mathrm{X} & \mathrm{X}\end{array}$

$\mathrm{X} \quad \mathrm{X}$

$\mathrm{X} \times$

$\mathrm{X} \times$

Note. $I_{1,2,3}=$ Three CBl interventions and assessments.

${ }^{a}$ All participants received treatments at all of the intervention sessions.

Figures 1 - 3 show the Precontemplation, Contemplation, and Preparation stages of change, respectively, and the mean user satisfaction with the two $\mathrm{CBI}$ 
treatment conditions across the three intervention sessions. Figure 1 shows that, in the Precontemplation stage of change, mean user satisfaction for the ALA and the TTM condition varied by intervention session with TTM $>A L A$ at Session 1, ALA > TTM at Session 2, and TTM about equal to ALA at Session 3. This variation appears to be the source of what was close to an interaction effect. Because no trend is apparent, the relationship that appears in Figures 2 and 3 represents more interpretable results.

Figures 2 and 3 show that the distinction between user satisfaction with the two $\mathrm{CBI}$ conditions was greater in the Preparation than the Contemplation stage of change.

Figure 1. Mean user satisfaction for computer based instruction treatments by the precontemplation stage of change over time.

\section{Precontemplation}

$$
\text { - } 1 \text { - Transtheoretical } \rightarrow \text { American Ling Assoc. }
$$

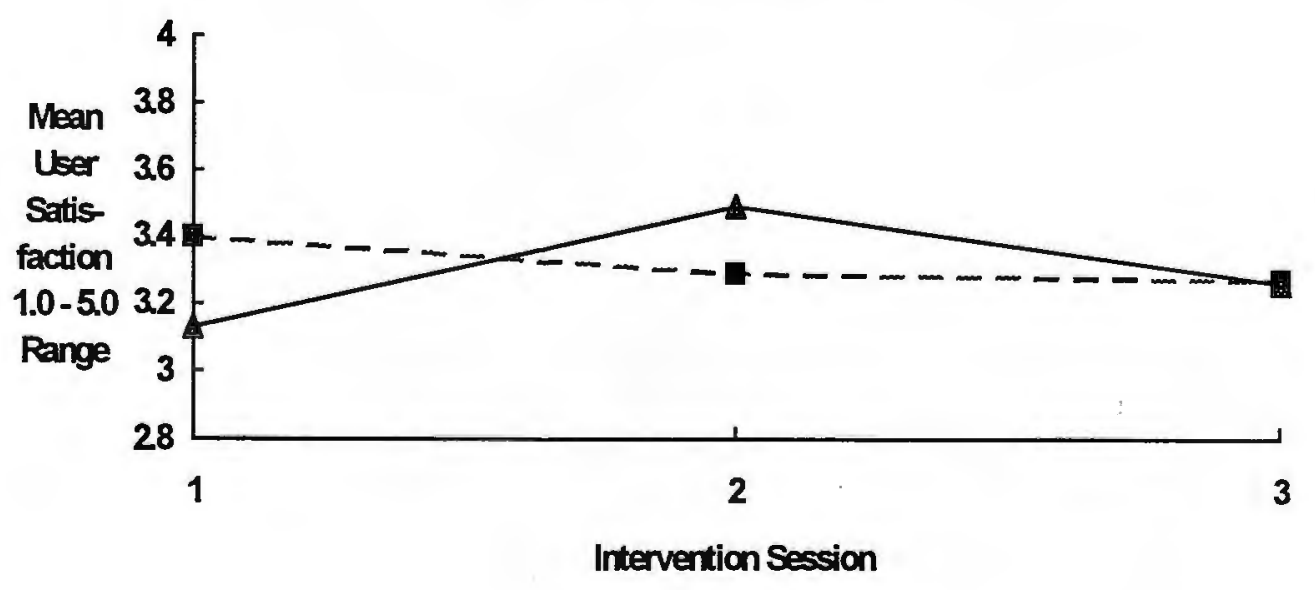


Figure 2. Mean user satisfaction for computer based instruction treatments by the contemplation stage of change over time.

\section{Contemplation}

$$
-4-\text { Transtheoretical —-American Lung Assoc. }
$$

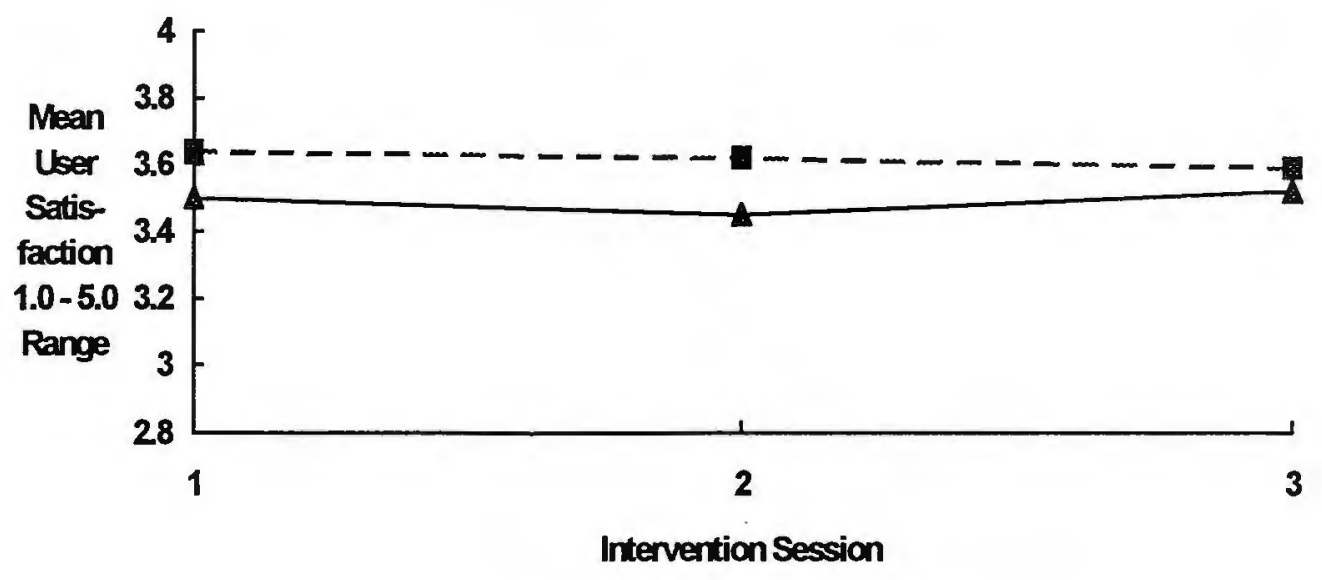

Figure 3. Mean user satisfaction for computer based instruction treatments by the preparation stage of change over time.

Preparation

$-4-$ Transtheoretical - - American Lung Assoc.

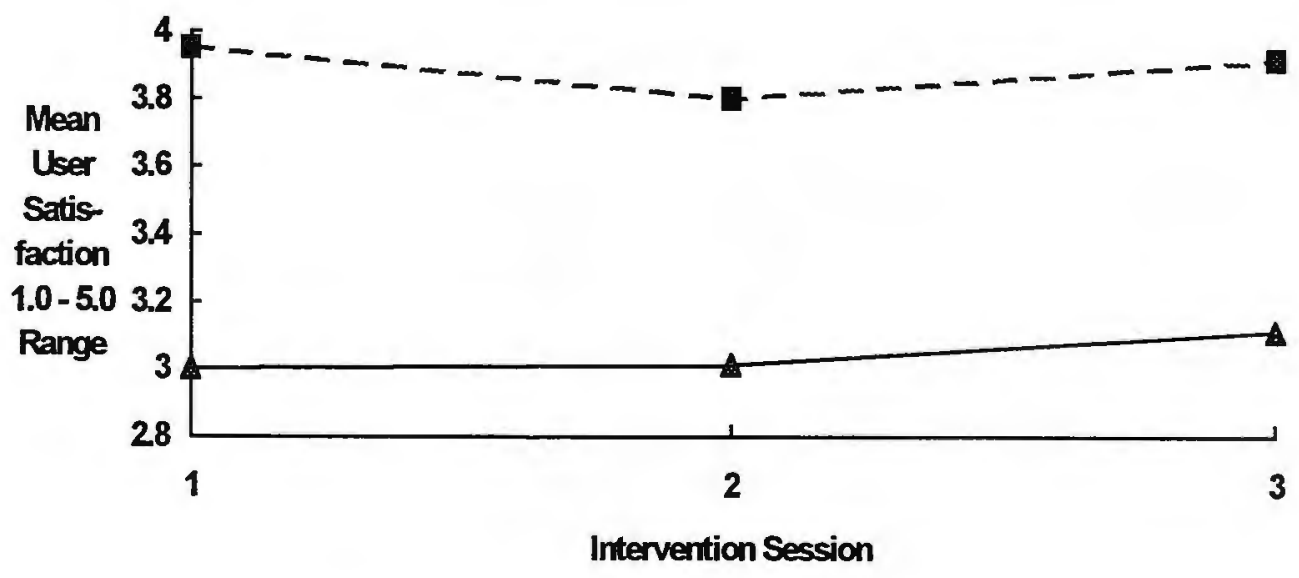


Figures 4 - 6 show, for Intervention Sessions 1 - 3 respectively, the mean user satisfaction with the two $\mathrm{CBI}$ treatment conditions across the Precontemplation, Contemplation, and Preparation stages of change. The results are similar to those for Figures 1 - 3 . Figure 5 shows, perhaps more clearly, the source of the near interaction as the isolated case when user satisfaction was rated higher for the ALA than the TTM treatment condition, during Intervention Session 2 in the Precontemplation stage of change. Figure 6 shows at Session 3 for Precontemplation that there is a nearly identical mean user satisfaction rating for the two $\mathrm{CBI}$ conditions and this probably adds to the near interaction effect.

Figure 4. Mean user satisfaction for computer based instruction treatments by stage of change at intervention session 1.

\section{Intervention Session 1}
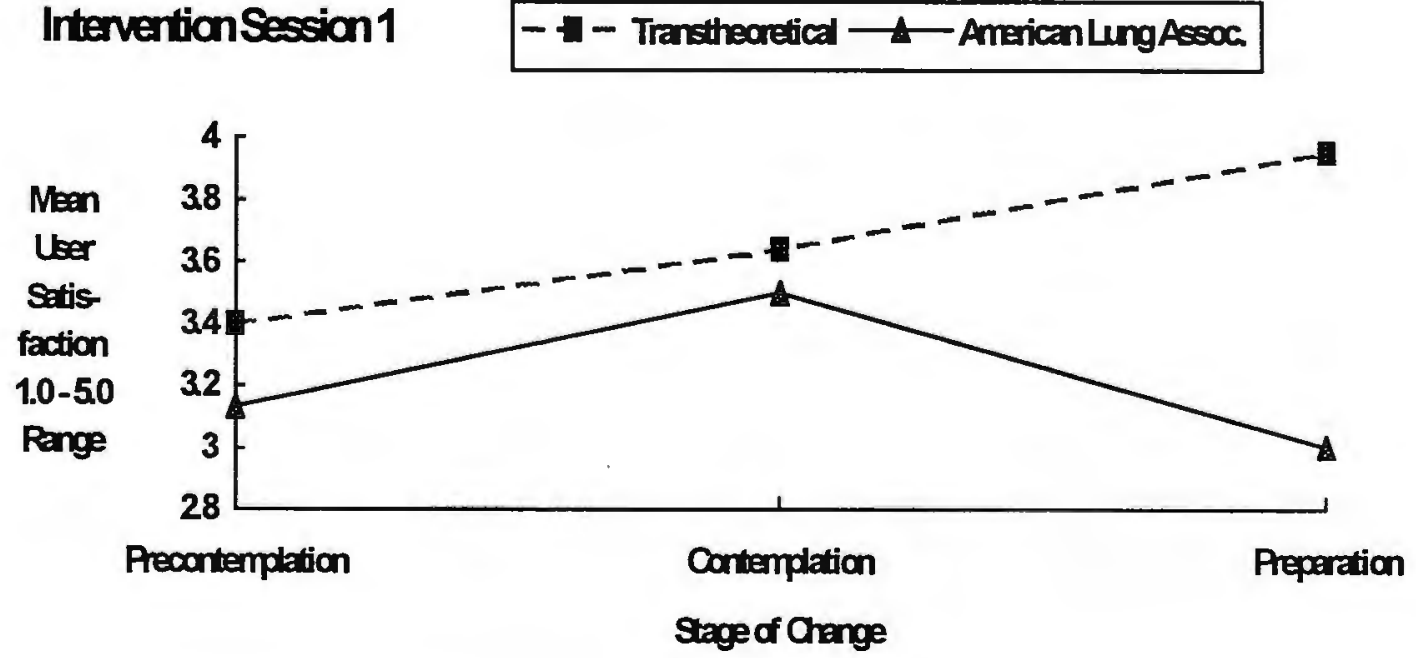
Figure 5. Mean user satisfaction for computer based instruction treatments by stage of change at intervention session 2.
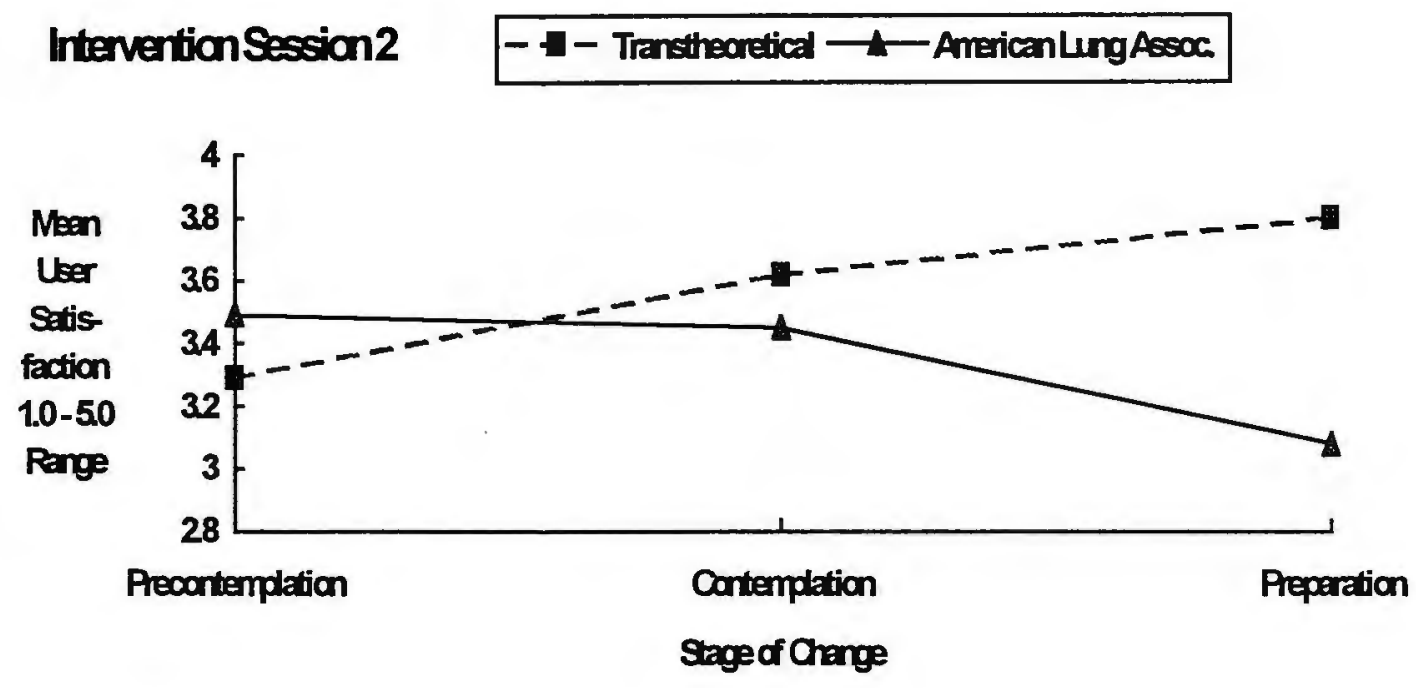

Figure 6. Mean user satisfaction for computer based instruction treatments by stage of change at intervention session 3.

Intervertion Session 3
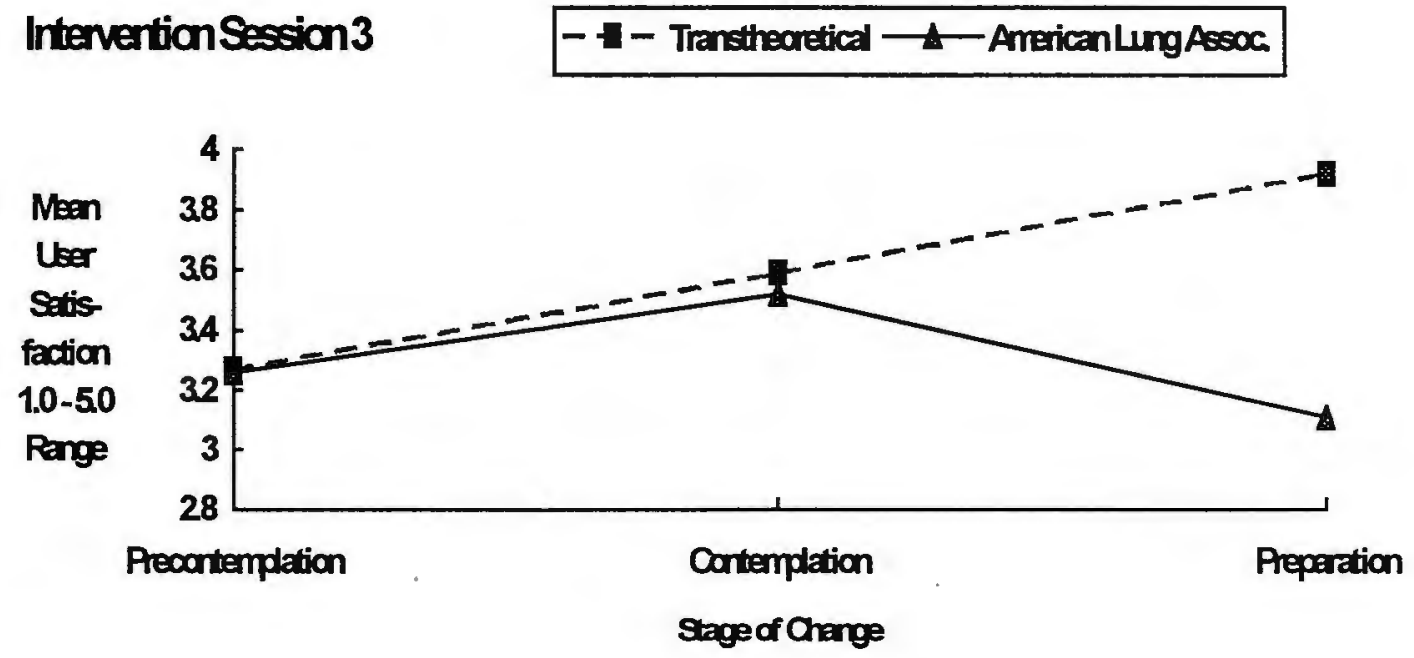


\section{Treatment x Gender x Time Repeated Measures ANOVA}

\section{Between-subject Treatment main effect}

There was a significant effect $(F(1,95)=4.76, p<.05)$ for Treatment, with user satisfaction rated more positively for the $T T M(N=62, \underline{M}=3.55, \underline{S D}=0.78)$ than the $A L A(N=37, \underline{M}=3.24, \underline{S D}=0.91) C B I$ condition. An ANOVA summary table is located in Table D-2 of Appendix D, showing the between and within sources of variation.

\section{Within-subject Treatment $\times$ Gender $\times$ Time interaction effect}

There was also a significant Treatment $x$ Gender $\times$ Time interaction effect $(F(2,190)=3.21, p<.05)$ in the within-subject condition as shown in Figures 7 and 8 . Figure 7 shows that the source of the interaction to be at intervention Session 2, when females did not evaluate user satisfaction differently for the two $\mathrm{CBI}$ treatment conditions. Considering the above significant treatment main effect, no main effect for gender, and no apparent trend, this interaction effect did not appear to be meaningful and, therefore, no further follow-up analysis was conducted.

\section{Relation of PC Experience, Pros \& Cons, Satisfaction, \& Sessions}

The degree of relationship among prior computer experience, Pros and Cons to smoke, and user satisfaction was also analyzed at each intervention session. First, zero order correlations among these variables were examined at each time point. Second, three step-wise multiple regression analyses were conducted in which the evaluative user satisfaction subscale was regressed 
Figure 7. Mean user satisfaction for the computer based instruction treatment $x$ females over time interaction effect.
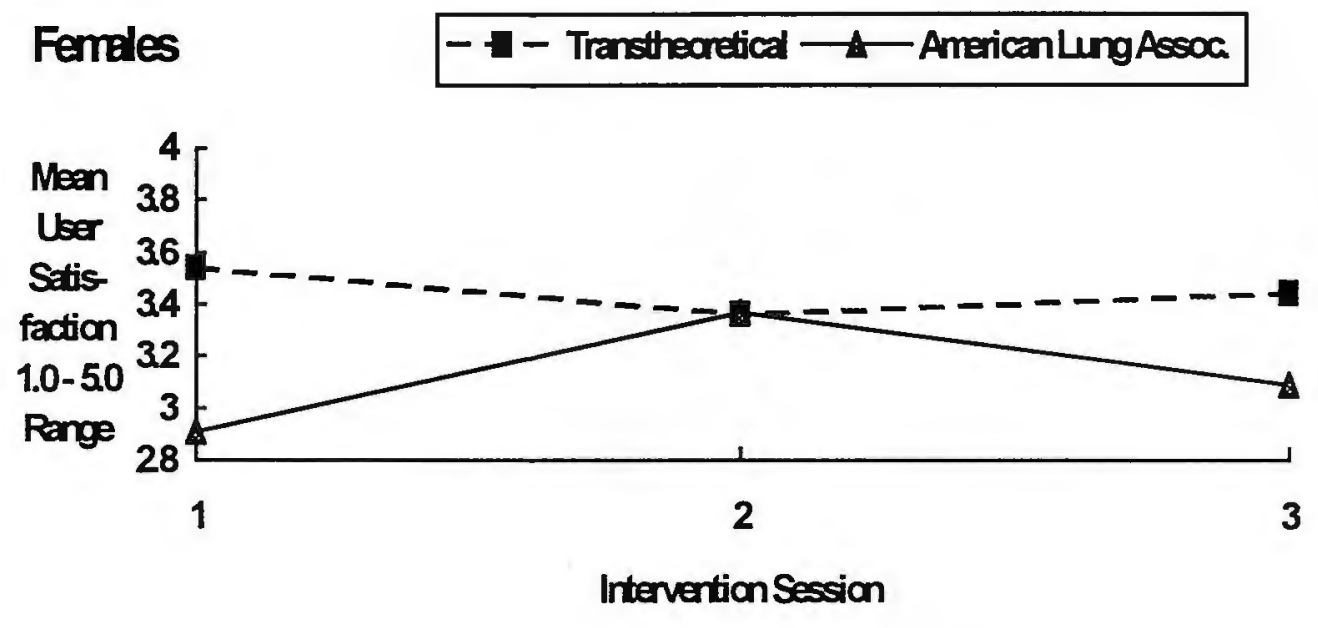

Figure 8. Mean user satisfaction for the computer based instruction treatment $x$ males over time interaction effect.
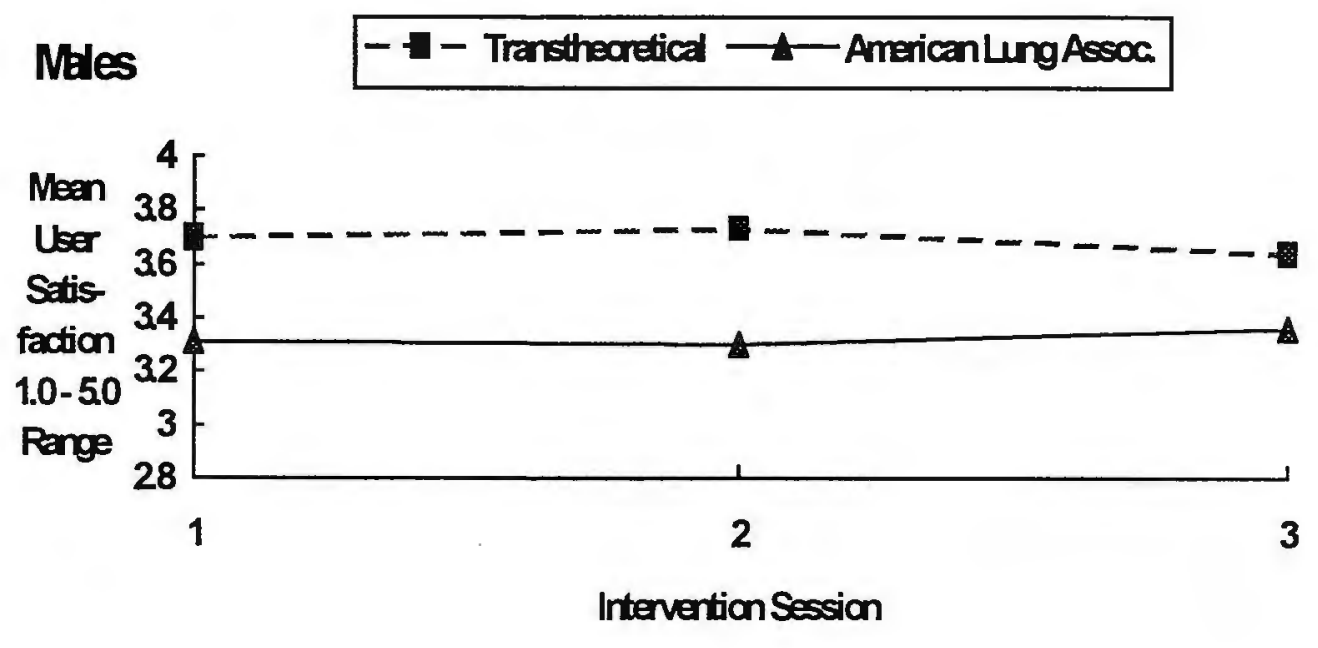
upon PC experience and the Pros and the Cons of smoking at each of the three intervention time points. The linear combination of variables that optimally predicted evaluative user satisfaction at each time point resulted from these analyses. Analyses were performed using SPSS REGRESSION. No cases had missing data and no suppresser variables were found.

Tables 6, 7, and 8 display, for Intervention Sessions 1, 2, and 3 respectively, the correlations between the variables, the unstandardized regression coefficients (B) and intercept, the standardized regression coefficients $(\beta)$, the semipartial correlations $\left(s r^{2}\right)$, and $R, R^{2}$, and adjusted $R^{2}$ after entry of the independent variables.

Table 6 shows that, for Intervention Session 1, two of the three Independent Variables were entered as a significant predictor in the stepwise regression. Pros for smoking (PROS, $s r^{2}=.024$ ) and Cons for smoking (CONS, $\left.\mathrm{sr}^{2}=.075\right)$ contributed significantly to prediction of evaluative user satisfaction. The $\mathrm{R}$ for regression was significantly different from zero at the end of the two steps. After the end of step 1, with Cons entered in the equation, $R=.27$, $F(1,161)=13.11, p<.001$. After the end of step 2 , with Pros and Cons entered in the equation, $R=.32, F(2,161)=8.85, p<.05$. The addition of Pros to the equation resulted in a significant increment in $R^{2}, F_{\text {inc }}(1,161)=4.32, p<.05$. PC experience (PCEXP) did not significantly improve $\mathrm{R}^{2}$ and therefore was not entered into the equation to optimally predict user satisfaction at Intervention Session 1. 
Table 6. Stepwise Multiple Regression of User Satisfaction on PC Experience and Pros and Cons of Smoking at Intervention Session 1

\begin{tabular}{lccccccc} 
Variables & $\begin{array}{c}\text { SATISFAC } \\
\text {-TION(DV) }\end{array}$ & CONS & PROS & PCEXP $^{\mathrm{b}}$ & B & B & $\begin{array}{c}\text { sr }^{2} \\
\text { (Incremen }^{2}\end{array}$ \\
\hline CONS & .27 & & & $-.33^{*}$ & -.16 & $.075^{*}$ \\
PROS & -.17 & -.05 & & & $.39^{*}$ & .27 & $.024^{*}$
\end{tabular}

$\begin{array}{llll}\text { PCEXP }^{\mathrm{b}} & -.07 & .11 & -.07\end{array}$

Intercept $=31.08$

$\begin{array}{lllll}\text { Means } & 34.58 & 20.06 & 13.07 & 3.23\end{array}$

Standard

deviation

$\begin{array}{llll}8.75 & 5.99 & 4.14 & 1.27\end{array}$

$$
\begin{array}{ll} 
& \mathrm{R}^{2}=.10 \\
\text { Adjusted } & \mathrm{R}^{2}=.09 \\
& \mathrm{R}=.32
\end{array}
$$

$p<.05$

${ }^{a} E$ Evaluative user satisfaction (dependent variable).

${ }^{\mathrm{b}} \mathrm{PC}$ experience.

Table 7 shows that one of the three Independent Variables was entered as a significant predictor in the stepwise regression for Intervention Session 2. Cons for smoking (CONS, $\mathrm{sr}^{2}=.149$ ) contributed significantly to prediction of evaluative user satisfaction. $\mathrm{R}$ for regression was significantly different from zero at the end of step 1. After the end of step 1, with Cons entered in the equation, $R=.39, F(1,118)=20.61, p<.001$. Pros and $P C$ experience did not reliably improve $\mathrm{R}^{2}$ and therefore were not entered into the equation to optimally predict evaluative user satisfaction at Intervention Session 2.

Table 8 shows that one of the three Independent Variables was also entered as a significant predictor in the stepwise regression for Intervention 
Table 7. Stepwise Multiple Regression of User Satisfaction on PC Experience and Pros and Cons of Smoking at Intervention Session 2

\begin{tabular}{|c|c|c|c|c|c|c|c|}
\hline Variables & $\begin{array}{l}\text { SATISFAC } \\
\text {-TION(DV) }\end{array}$ & CONS & PROS & PCEXP & B & $B$ & $\begin{array}{c}\mathbf{s r}^{2} \\
\text { (Incremental.) }\end{array}$ \\
\hline CONS & .39 & & & & $.47^{*}$ & .39 & $.149^{\circ}$ \\
\hline PROS & -.06 & -.03 & & & & & \\
\hline PCEXP & -.05 & .13 & -.05 & & & & \\
\hline & \multicolumn{7}{|c|}{ Intercept $=25.42$} \\
\hline Means & 34.63 & 19.52 & 12.68 & 3.23 & & & \\
\hline
\end{tabular}

Standard

deviation

$\begin{array}{llll}8.12 & 6.63 & 3.71 & 1.27\end{array}$

$\begin{array}{ll} & \mathrm{R}^{2}=.15 \\ \text { Adjusted } & \mathrm{R}^{2}=.14 \\ & \mathrm{R}=.39\end{array}$

$p<.05$

${ }^{a}$ Evaluative user satisfaction (dependent variable).

${ }^{\mathrm{b}} \mathrm{PC}$ experience.

Table 8. Stepwise Multiple Regression of User Satisfaction on PC Experience and Pros and Cons of Smoking at Intervention Session 3

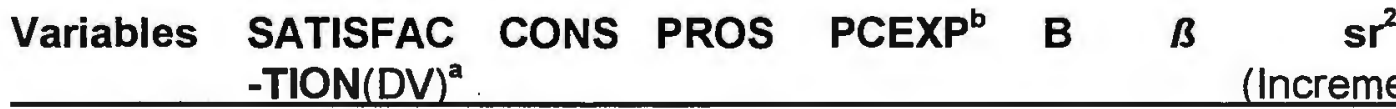

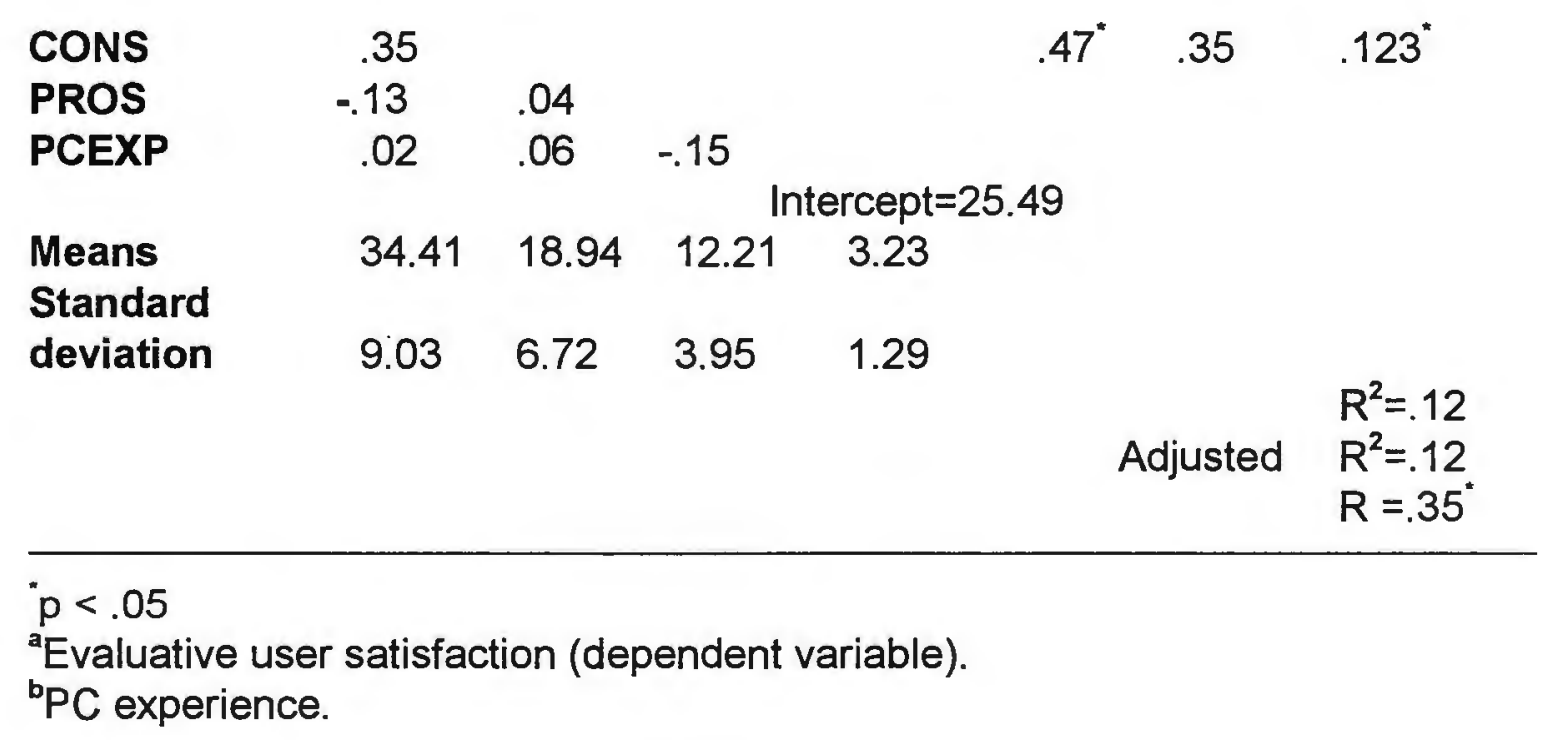


Session 3. Cons for smoking (CONS, $s r^{2}=.123$ ) contributed significantly to prediction of evaluative user satisfaction. $\mathbf{R}$ for regression was significantly different from zero at the end of step 1. After the end of step 1, with Cons entered in the equation, $R=.35, F(1,106)=14.86, p<.001$. Pros and $P C$ experience did not reliably improve $\mathrm{R}^{2}$ and therefore were not entered into the equation to optimally predict user satisfaction at Intervention Session 3. 


\section{DISCUSSION}

Two of the predictions in this study were confirmed and four were not. However, the CBI literature that was found applicable to this study was mostly confirmed. Looking back at each hypothesis and the obtained results, the following implications are offered.

\section{Computer Based Instruction Treatment}

It was predicted that satisfaction ratings would significantly differ for the TTM and ALA conditions. The Gender $x$ Treatment $x$ Time ANOVA summarized in Table D-2 showed that the satisfaction ratings were higher for the TTM than the ALA condition. For the 10 item Evaluative Scale, users were more satisfied with the Transtheoretical than the ALA computer based instruction intervention for smoking cessation. The Stage of Change $x$ Treatment $x$ Time ANOVA summarized in Table D-1 supported the same result with a nearly significant treatment effect.

\section{Gender}

Based on literature reviewed for this study, it was predicted that males would have significantly different user satisfaction than females. The ANOVA summarized in Table D-2 showed that, in this study, the males did not have significantly different user satisfaction than females. This finding supports Deardorff's (1986) overall finding of no gender differences. This lack of 
difference in satisfaction ratings indicates that gender need not be known and used in order to maximize user satisfaction with $\mathrm{CBI}$ interventions for smoking cessation. In other words, CBI using the TTM condition appears to be equally satisfactory for both females and males.

\section{Stage of Change}

It was predicted that satisfaction would significantly differ across the stages of change. The ANOVA summarized in Table D-1 showed that satisfaction did not significantly differ across the stages of change. This neither supports nor differs from the literature, since none was available for the relation of stage of change to user satisfaction with a CBI intervention. This indicates that stage of change need not be known and used in order to maximize user satisfaction with the $\mathrm{CBI}$ interventions for smoking cessation.

However, nearly significant trends shown in Figures 1- 6 suggested that the participants in the Preparation stage of change consistently had the most increased satisfaction with the Transtheoretical compared to the ALA interventions for smoking cessation. The satisfaction rating was consistently higher by about one (1) point out of the 5-point semantic differential scale. The participants in the Contemplation stage of change also consistently rated satisfaction higher for the Transtheoretical compared to the ALA condition, although only about 0.1 higher, whereas this was not the outcome for the participants in the Precontemplation stage of change at Intervention Sessions 2 
and 3. This information indicates that the Transtheoretical CBI program may be most satisfactory to participants in the Preparation stage of change.

While not significant, the trend resulting mainly from higher satisfaction with the Transtheoretical CBI intervention for participants in the Preparation stage of change has alternative explanations and implications. It might be explained by the fact that the other participants were in the Precontemplation or Contemplation stages, not the Preparation stage which involves readiness to take action. Since the Transtheoretical Model is designed to be effective at each stage, but was evaluated higher for the participants in the Preparation stage (see Figures $1-6$ ), the computer based TTM program in this study may have been too action oriented for participants in the Precontemplation and Contemplation stages of change. Furthermore, since the ALA was less satisfying to users than was the TTM program, perhaps the ALA program was not perceived as action oriented or was not as effective an action oriented program for smoking cessation.

An alternative explanation for the nearly significant trends shown in Figures $1-6$ again comes from the dynamics of the Transtheoretical Model. Participants in the Precontemplation and Contemplation stages of change may have needed more time than this study covered TTM treatment effects and any related user satisfaction to be detected. 


\section{Session}

A need for more time than this study covered may also explain the analyses for effects of the sessions, which were relatively close in time. The ANOVAs summarized in Tables D-1 and D-2 showed that user satisfaction did not significantly differ across the intervention sessions of this study. This finding did not support that by Chin et al. (1987), which found that user satisfaction increased over time. Yet, the present study did find a sustained relation of reasons not to smoke (Cons) to user satisfaction across all three intervention sessions.

\section{Computer Experience}

It was predicted that prior computer experience would significantly relate to user satisfaction ratings. Tables 6,7 , and 8 showed that prior computer experience did not significantly relate to user satisfaction ratings, for any of the three intervention sessions. This finding supports the Deardorff (1986) and Wallace et al. (1988) findings that prior computer experience was not a significant factor in user satisfaction. This finding suggests that prior computer experience need not be known and used in order to maximize user satisfaction with $\mathrm{CB}$ l interventions for smoking cessation.

\section{Decisional Balance}

It was predicted that reasons to smoke (Pros) and not to smoke (Cons) would significantly relate to user satisfaction ratings. Table 6 showed that, for 
Intervention Session 1, Pros and Cons did significantly relate to user satisfaction ratings. The results neither support or differ from the literature, since none was available for the relation of decisional balance to user satisfaction with a $\mathrm{CBI}$ intervention.

Tables 7 and 8 showed that only Cons relate to user satisfaction for Intervention Sessions 2 and 3. The effect size for Cons increased over time. The $\mathrm{CBI}$ delivery of reasons not to smoke (Cons) supported and sustained increased user satisfaction. The Transtheoretical program emphasized the most Cons for participants in the Precontemplation and Contemplation stages of change and this was related to the increased user satisfaction self reported by these participants.

The relation of Pros to user satisfaction in Session 1 is less clear. It could mean that participants in the Precontemplation stage of change, who would most identify with reason to smoke, either progressed in stage of cessation or lost interest in the $\mathrm{CBI}$ sessions for smoking cessation over time.

\section{Conclusion}

The relation of reasons for not smoking (Cons) to user satisfaction across all three intervention sessions is an interesting finding, considering the law of diminishing returns that governs satisfaction with use of most consumer products in our society. For example, the satisfaction from consuming food when hungry diminishes as we use more of it. The consistent relationship of Cons to user satisfaction over time may indicate that people trying to stop smoking are 
interested in the negative aspects of smoking, perhaps to strengthen their decision to quit. This study suggests that future studies will do well to further explore and utilize the decisional balance tool.

The present study showed that, as Allen (1986) found, the evaluative dimension is a useful measure of user satisfaction. This study also indicated that an activity-potency scale may be useful in a future, expanded study. The PCA Component II item loadings (See Table 3) were either high or low, indicating that the activity-potency scale is potentially a strong one. It appears that more items would load on this activity-potency scale with high internal consistency, making it a useful scale, had a larger number of potential items for this scale been included in the study. In addition to how more items could be included, consideration should also be given to whether other dimensions could be developed in future research.

This study indicated that changes in the Transtheoretical CBI intervention might increase user satisfaction: (1) Further study should give attention to whether the interventions for the Precontemplation and Contemplation stages of change are too action oriented; (2) Further study should consider including more sessions so that a longer time period is observed; and (3) Further study should determine if more complete multimedia (video, animation, music, and sound effects) than included in this study will increase user satisfaction. Although the TTM condition was rated as having significantly higher user satisfaction than the ALA treatment condition, neither CBI intervention was rated near the top of the 5-point semantic differential scale. As presented, Chin et al. (1988) and 
Weisberg (1988) indicated that higher satisfaction should translate into higher effectiveness of the behavior change intervention, e.g., higher effectiveness of the Transtheoretical CBI program in the core study.

Future studies may also broaden both the understanding and effectiveness of $\mathrm{CBI}$ for health education in our society by including a larger number of minority participants. A larger number of minority participants will enable analyses of the relationships of subject diversity, program effectiveness, and user satisfaction.

Useful information follows from findings of both the significant differences and relationships in this study and the lack there of. This study found a lack of significant differences and relationships in user satisfaction for females and males, for prior computer experience, in the three stages of change, and over the three intervention sessions of this study. These findings indicate that no need for special attention to gender, computer experience, stage of change, or time, to realize the higher satisfaction from use of the Transtheoretical CBI program.

Future studies are encouraged to use the results from this, and other preliminary investigations, for the continued and more detailed development of a standard instrument which needed to measure user satisfaction with CBI. 


\section{APPENDICES}


Appendix A

User Satisfaction Evaluation Screens 


\section{User Satisfaction Evaluation Screens}

\section{Example Screens}

Prints of two actual screens views are provided at the end of this Appendix A.

These prints represent the way the screens actually appeared to the study participants as they responded to the user satisfaction questionnaire.

\section{Introductory Screen for All Sections}

Just one more thing! We would like to know what you think of this program.

Please tell us what you liked and disliked about the things you have done here today by answering a few questions. It will help us to make the program better for others like yourself.

\section{All Interactive Screens}

\section{Screens 1-20 header}

Please choose the number that best shows your opinion about this session. You must still use the buttons on your right to enter your answers. 


\section{User Satisfaction Questionnaire}

\section{Screens 1-15 sub-header}

This session was

\section{Screens 1-15}

(Screen layout was vertical and top to bottom, rather than horizontal and left to right as shown below.)

1.) Unpleasant 54321 Pleasant

2.) Short 54321 Long

3.) Bad 54321 Good

4.) Cold 54321 Friendly

5.) Worthless 54321 Valuable

6.) Boring 54321 Interesting

7.) Threatening 54321 Relaxing

8.) Fast 54321 Slow

9.) Confusing 54321 Clear

10.) Wonderful 54321 Terrible

11.) Satisfying 54321 Frustrating

12.) Stimulating 54321 Dull

13.) Easy 54321 Difficult

14.) Pleasing 54321 Irritating

15.) Simple 54321 Complicated 
Identified System Areas

\section{Screens $16-18$ scale}

5 - Strongly disagree

2 - Agree

4 - Disagree

1 - Strongly agree

3 - Neutral

\section{Screens 16-18}

16.) I like the way the information appeared on the screen.

17.) I had enough time to finish each screen.

18.) I learned a lot about smoking and myself.

\section{Prior Computer Experience}

\section{Screens 19-20 scale}

5 - About daily

2 - A few times

4 - About weekly

1 - Never

3 - Once a month or so

\section{Screens 19-20}

19.) Before this session, how often have you used a computer?

20.) Before this session, how often have you used a mouse with a computer? 


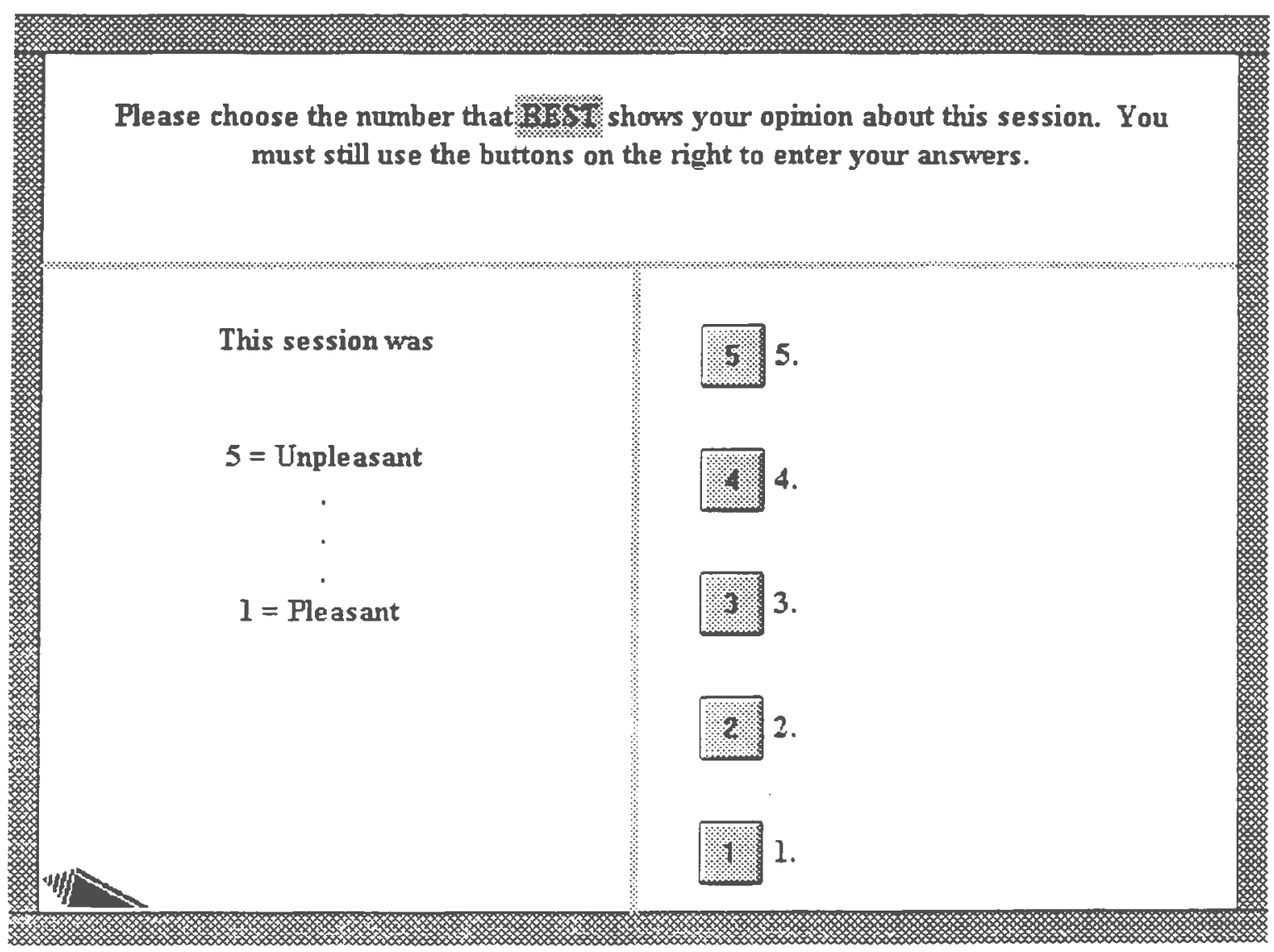


Please choose the number that 1 in o. shows your opinion about this session. You must still use the buttons on the right to enter your answers.

\section{This session was}

$$
\begin{gathered}
5=\text { Boring } \\
\cdot \\
\text { I }=\text { Interesting }
\end{gathered}
$$

\%. 5.

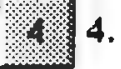

\%. 3.

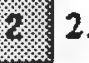

1 . 1 . 


\section{Appendix B}

Baseline Questionnaire 


\section{HEALTH QUESTIONNAIRE PART I}

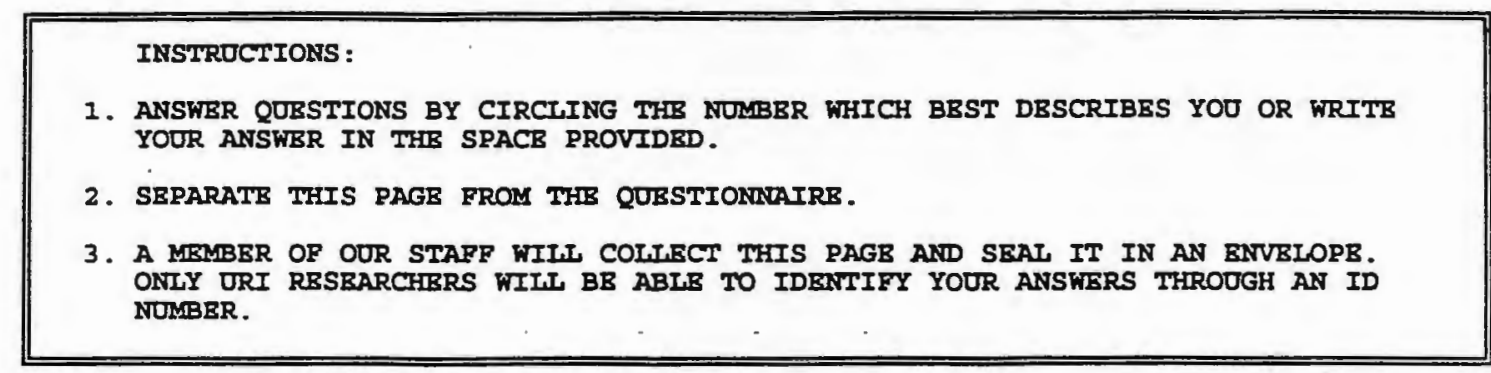

Your name:

First $\overline{\text { M.I. }}$ Iast

Nickname you are using:

Date of Birth: $\frac{}{\text { Month }} / \overline{\text { Day }}{ }^{197} \overline{\text { Year }}$

1. Choose the category which best describes you.

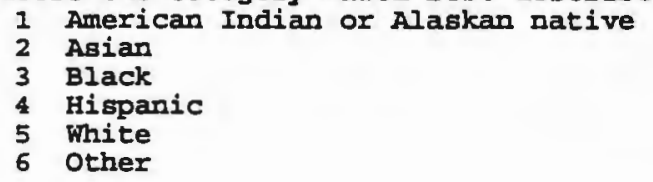

2. Gender

$$
\begin{array}{ll}
1 & \text { Pemale } \\
2 & \text { Male }
\end{array}
$$

3. Do you spend most of your time with one group of friends?

$$
\begin{array}{ll}
1 & \text { Yes } \\
2 & \text { No }
\end{array}
$$

4. Who are the members of this group?

1 Mainly boys

2 Mainly girls.

3 Both boys and girls

4 I do not belong to any special group

5. What grade are you in?

$$
\begin{aligned}
& 1 \\
& 2 \text { 10th grade } \\
& 3 \text { 11th grade } \\
& 4 \text { 12th grade }
\end{aligned}
$$

6. Which of the following programs are you enrolled in?
1 General program
2 College entrance (college prep) program 


\section{HEALTH QUESTIONNAIRE PART II}

7. Have you ever used chewing tobacco or snuff?

1 Yes

2 No

8. If you use chering tobacco or snuff, how often have you used it

In the last 7 days?

Not at all

Once

A few times

About once a day

About 2 to 5 times a day

About 6 to 10 times a day

About 10 to 20 times a day

More than 20 times a day

9. Have you stopped using chewling tobacco or snuff?

1 Yes, I stopped more than 6 months ago

Yes, I stopped, but less than 6 months ago

No, but I intend to stop in the next 30 days

No, but $I$ intend to stop in the next 6 months

No, and I do not intend to stop in the next 6 months

I have never used chewing tobacco or snuff

10. Have you ever smoked clgarettea?

1. No, I have never tried smoking

Yes, but only one puff

Yes, but only some puffs

Yes, a few times

Yes, but not regularly

Yes, regularly

I used to smoke but I quit

11. How much do you currently smoke?

1 I have never smoked

2 Not at all in the last 12 months

3 A few times in the last 12 months

Usually once a month

A few times a month

Usually once a week

A fex times each week

A few times most days

About half a pack each day

10 A pack or more each day

12. Do both of your parents live with you?

1 Yes

2 No, only my mother or stepmother

3 No, only my father or stepfather

4 Neither

13. Does your father/stepfather smoke clgarettea?

1 . Yes

2 No

3 Does not apply

14. Does your mother/stepmother smoke cigarettes?

1 Yes

2 No

3 Does not apply

15. Do any of your sisters or brothers smoke clgarettes?

1 Yes

2 No

3 I don't have a sister or a brother 
16. How many of your frlends gmoke clgaretted?

1 None

2 Only a few

3 Less than half

4 About half

5 Nore than half

6 Almost all

17. Does your best frlend currently smoke clgarettes?

1 Yes

2 No

3 I do not have a best friend

18. Which of the following best describes your current amoklng?

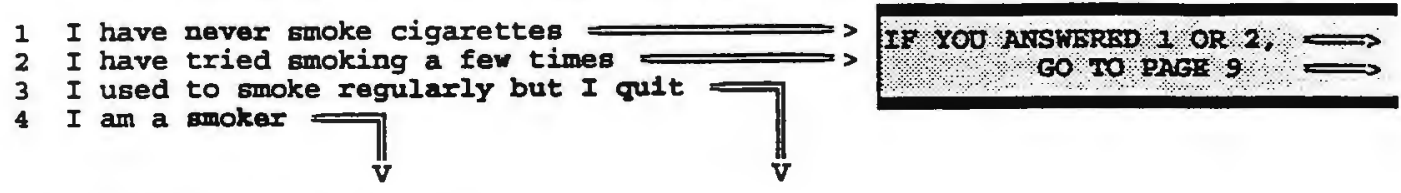

19. Bave you atoppad smoking clgarettes?

1 Yes, I stopped more than 6 months ago

2 Yes, I stopped, but less than 6 months ago

3 No, but I intend to quit in the next 30 dave

4 No, but I intend to quit in the next 6 months

5 No, and $I$ do not intend to guit in the next 6 months

20. How many cigarettes have you smoked in the lagt 24 hourg?

cigarette日

21. About how many cigarettes did you smoke in the last 7 days?

cigarettes

22. How frequently have you smoked elgarettes during the past 30 days?

1 Not at al1

2 Less than one cigarette per day

1 to 5 cigarettes per day

About a half $(1 / 2)$ pack per day

About one pack per day

About one and half $(1,1 / 2)$ packs a day

7 packs or more per day

23. If you have quit smoking, how many cigarettes did you use to smoke before you quit amoking?

1 A few cigarettes a month or less

2 About 1 to 6 cigarettes per week

4 About 1 cigarette per day

5 About 2 to 5 cigarettes per day

6 About a $1 / 2$ pack per day or more

7 I have not quit smoking

24. How long have you been smoking cigarettes regularly? If you bave quit,

for how long had you been smoking before you quit?

1 Less than 3 months

3 .to 6 months

6 to 12 months

1 to 2 years

2 to 3 years

3 to 4 years

4 to 5 years

5 to 6 years

More than 6 years

25. Are you seriously considering quitting gmoking within the next 6 months?

1 Yes

2 No

3 I have quit already 
26. Are you planning to quit smoking in the next 30 dare?

1 Yes

2 No

3 I have quit already

27. How many times have you tried very hard to quit smoking cigarettes since you started to amoke cigarettes regularly?

0 Never

11 time

22 times

33 times

44 times

55 times

66 or more times

28. If you amoke, when was the last time you seriously tried to gult gmoking?

1 During the last month (30 days)

22 to 3 months ago

34 to 6 months ago

46 to 12 months ago

5 More than 12 months ago

6 Never

7 I have quit

29. How much presaure have you felt from your family, friends, or others to quit smoking?

1 No pressure

2 Slight pressure

3 Loderate pressure

4 Extreme pressure

CIRCLE 1 IF YOO THE FOLLOWING STATEMESTS ARB NOT IMPORTANT TO YOO. CIRCLE 5 IF THE STATEMENTS ARB EXTREMBLY IMPORTANT. IF YOD ARB IN BETWEEN, USB NUMBERS 2, 3, OR 4.

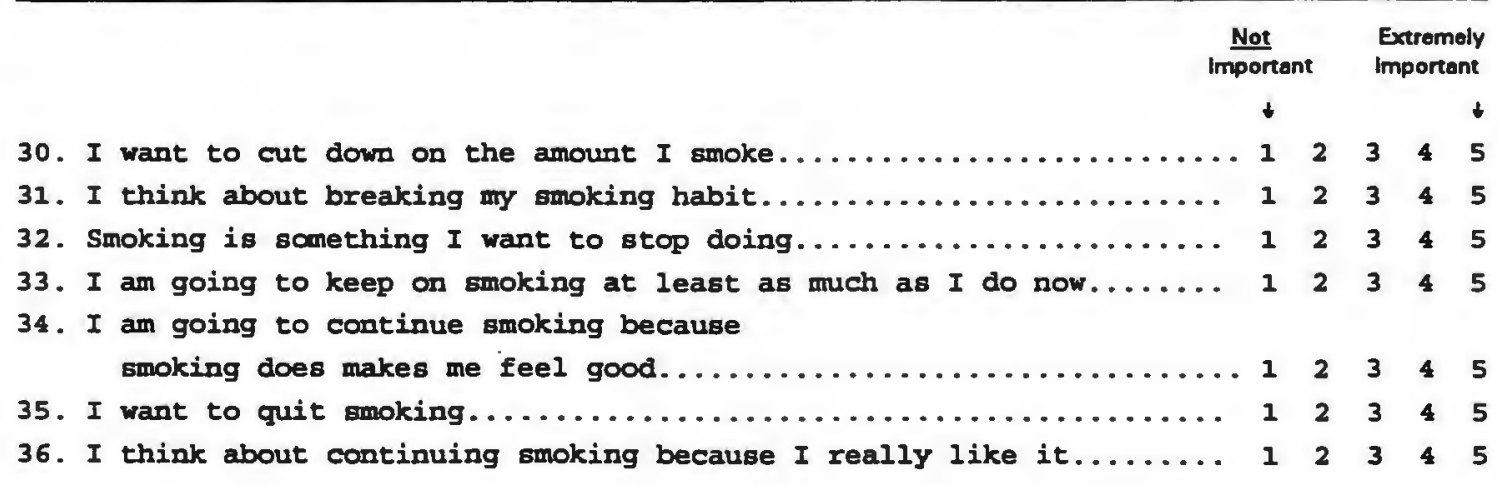

HOW TKMPTED WOULD YOU BE TO SMOKB IN THB FOLLONING SITUATIONS?

37. When I an with people who are smoking............ 1 2 - 3445

38. When $I$ an drinking......................... 1224345

39. When I am very anxious and stressed............. 1 2 3 3 $4 \quad 5$

40. When my friends are smoking and enjoying it........ 12 2 $3 \quad 4 \quad 5$

41. When I need sonething to get through a difficult day. $\begin{array}{lllll}1 & 2 & 3 & 4 & 5\end{array}$

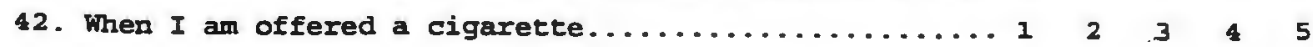




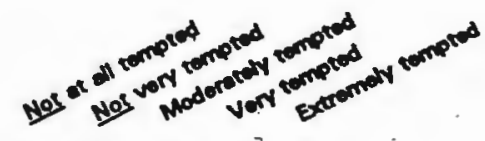

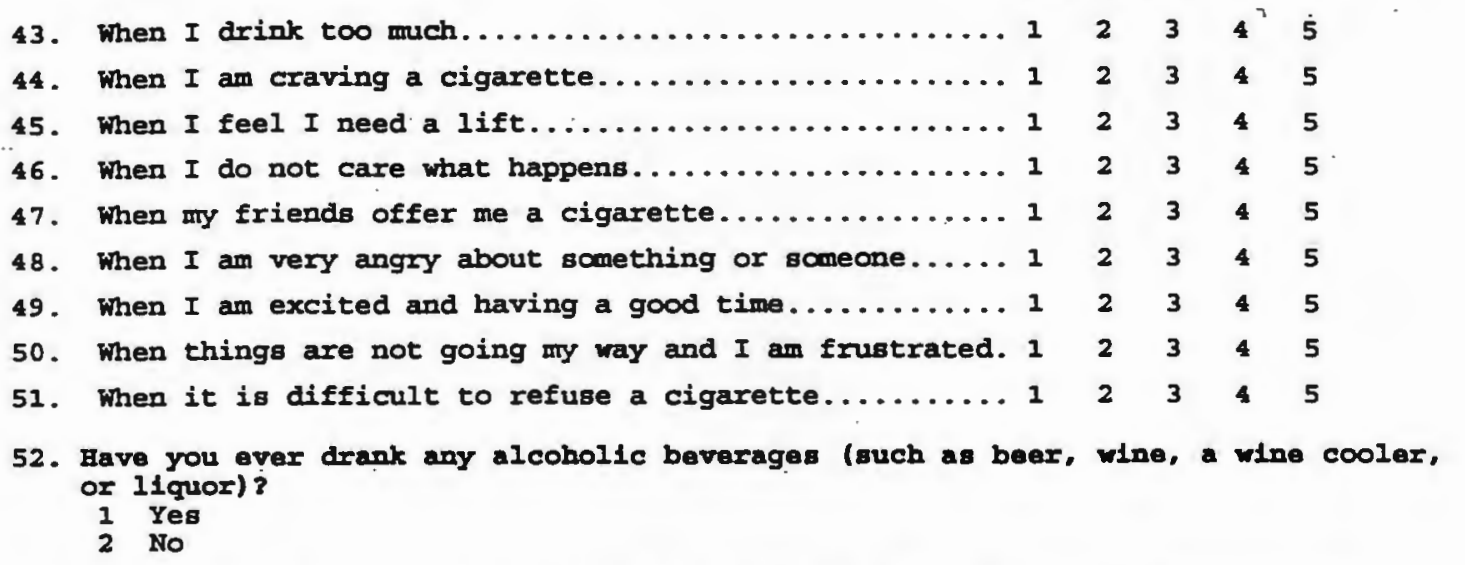

53. In the pest 30 days, on how many days did you drink any alcoholic beverages (such as beer, vine, a wine cooler, or liquor)? number of days

FOR THE FOLLOWING QUESTIONS ONR DRIMK BQWAI TO ONE BRER, A GLASS OF WINE, ONE SHOT (OUNCE) OF HARD IIQUOR, OR ONB WINE COOLER.

54. On days that you drink alcoholic beverages, how many drinks do you usually have? (If you do not drink, write 0. )

drinks

55. On days that you driak do you usualiy have 3 or more drinks?

1 YBS

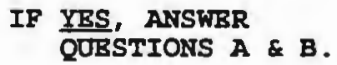

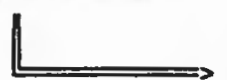

2 No, I usually drink less than 3 drinks

IF NO, ANSWER QUESTIONS C\& D

3 NO, I do not drink alcohol

IF NO, ANSWER QUESTIONS C \& D
A) How long have you been drinking 3 or more dinks?

1. Less than 3 month

2 Between 3 and 6 months

3 Between 6 months and 1 year

4 More than a year

B) Do you plan to cut down to less than 3 drinks? 10

2 Yes, in the next 6 montis

3 Yes. in the next 30 day

C) When did you stop drinking 3 or more dinks on days that you drank?

1 Thave never usually drunk 3 danks

2 Istopped less than 6 months a 00

3 istopped more than 6 months ago

D) Do you intend to start drinking 3 or more drinks on days that you drink?

1 Yes, in the next 30 days

2 Yes, in the next 6 months

3. No, / am not olanning to drink 3 drinks 
56. Do you drink 6 or more drinks evary now and then?

1 YBS

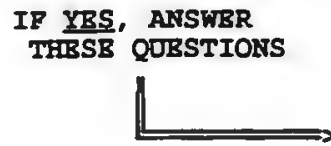

2 NO
A) How long have you been drinking 6 or more drinks every now and then?

1 Less than 3 month

2 Between 3 and 6 momths

3 Between 6 months and 1 year

4 More than a year

B) Do you plar to stop drinking 6 or more drinks?

1 No

$2 Y_{e s}$, in the naxt 6 months

3 Yes, in the next 30 days

C) When did you stop drinking 6 or more drinks?

I I have never drunk 6 or more drinks

2 Less than 6 months ago

3 More 6 months ago

D) Do you intend to drink 6 or more drinks every now and then?

1 Yes, in the next 30 days

2 Yes, in the next 6 months

3 No, I am not planning to drink 6 drinks

HOW IMTORTANT TO YOU ARB THB FOIIOWING STATEMIENTS IN YOUR DECISION TO DRINK OR TO NOT DRINK ALCOHOL.

IF YOU DO NOT DRINK, ARB ANY OF THB FOLIOWING STATEMENTS REASONS FOR YOT TO NOT DRINK OR REASONS THAT MAKG YOU WANT TO DRINK

CIRCIE 1 IF IT IS NOT IMPORTANT AT ALI AND 5 IF IT IS EXTREMIRLY IMPORTANT. IF YOU ARE IN BETWEEN USE NUMBERS 2, 3, OR 4 .

RATB THB TMPORTANCB TO YOUR DECISTOY TO

DRINK OR TO YOUR DECISION TO NOT DRIRK
Nor important at All
Extremoly

Important

57. If I buy alcohol then I have less money for other things . . . 1 2 3445

58. Drinking makes me more relaxed and less tense. . . . . . . . $\begin{array}{llllll} & 2 & 3 & 4\end{array}$

59. Drinking makes me less coordinated . . . . . . . . . . . . . $\begin{array}{lllll} & 2 & 3 & 4\end{array}$

60. I do not think as clearly when I drink . . . . . . . . . . . . 1 23345

61. Alcohol makes my sexual experiences easier and more enjoyable . $\begin{array}{llllll}2 & 3 & 4 & 5\end{array}$

62. Drinking helps me deal with problems . . . . . . . . . . . . 132345

63. Drinking is bad for my health . . . . . . . . . . . . . . . . 142345

64. Dnking helps give me energy and keep me going . . . . . . . . 132345

65. After drinking I often wake up feeling down . . . . . . . . . . $\begin{array}{llllll} & 2 & 3 & 4 & 5\end{array}$

66. Without alcohol my life would be more boring and dull . . . . $\begin{array}{llllll} & 2 & 3 & 4 & 5\end{array}$

67. I do not do as well at school because of my drinking. . . . . $\begin{array}{llllll}1 & 2 & 3 & 4 & 5\end{array}$

68. I am afraid that if I drink I will become an alcoholic . . . . 1 2 3445

69. When I drink I get less angry and less frustrated with others . $\begin{array}{llllll}1 & 2 & 3 & 4 & 5\end{array}$

70. My drinking makes me feel out of control . . . . . . . . . . $\begin{array}{lllll} & 2 & 3 & 4\end{array}$

71. Drinking helps me to have fun with friends . . . . . . . . . 132345 
72. Drinking causes problems with others . . . . . . . . . . . . . . 122345

73. I feel less lonely and sad when I drink . . . . . . . . . . . . . 122345

74. I seem to argue and fight more if I am drinking. . . . . . . $1 \begin{array}{llllll}2 & 3 & 4 & 5\end{array}$

75. Drinking makes me more careless . . . . . . . . . . . . . . . . 132434

76. I do things better when I drink . . . . . . . . . . . . . . . 1 2 . 345

77. I an losing the trust and respect of my friends and family because of my drinking . . . . . . . . . . . . . . . . 122345

78. I am better at sports after a few drinks of alcohol . . . . . . $1 \quad 2 \quad 3 \quad 4 \quad 5$

79. I do not like myself when I drink . . . . . . . . . . . . . . . . . . 122345

80. People seem to like me better when I an drinking . . . . . . $1 \begin{array}{lllll}2 & 2 & 4 & 5\end{array}$

81. I feel like I'm a slave to alcohol . . . . . . . . . . . . . . . 122345

82. I cas talk with people of the opposite sex better after a few drinks of alcohol . . . . . . . . . . . . . . . . $122 \quad 345$

83. I am setting a bad example for others with my drinking . . . $\begin{array}{llllll} & 2 & 3 & 4 & 5\end{array}$

84. I would lose my friends if I did not drink . . . . . . . . . . . . . $\begin{array}{llllll} & 2 & 2 & 4 & 4\end{array}$

85. Drinking could land me in trouble with the law. . . . . . . . 1424345

86. Drinking helps keep my mind off problems. . . . . . . . . . . 1325345

87. Parties are not as much fun if people are drinking alcohol . . $1 \quad 2 \quad 3 \quad 4 \quad 5$

88. Drinking helps me think better . . . . . . . . . . . . . . . . 122345

89. I don't like the way I an when I drink . . . . . . . . . . . . . 1224345

90. Drinking gives me more courage . . . . . . . . . . . . . . . . 122345

91. Beer, wine, and other alcoholic drinks cost too much . . . . . $122 \quad 345$

92. I feel sexier after a few alcoholic drinks . . . . . . . . . . . $1 \quad 2 \quad 3445$

93. Drinking could get me addicted to alcohol . . . . . . . . . . . 1 2 345

94. Do you ride in a friend's car when the driver bas been drinking?

1 Yes, but $I$ intend to stop in the next 30 days

2 Yes, but I intend to stop in the next 6 months

3 Yes, and I do not intend to stop in the next 6 months

4 No, I stopped in the last 6 months

5 No, I stopped more than 6 months ago

95. Do you exercise at least 3 times a week for at least 20 minutes each time?

1 Yes, I have been for more than 6 months

2 Yes, I have been, but for less than 6 months

3 No, but $I$ intend to in the next 30 days

4 No, but $I$ intend to in the next 6 months

5 No, and I do not intend to in the next 6 months

96. Do you feel that you are under a great deal of stress?

$$
\begin{array}{ll}
1 & \text { Yes } \\
2 & \text { No }
\end{array}
$$

97. Do you consider yourself overwelght?

1 Yes

2 No 
98. Have you been trying to loose welght?

1 Yes, I have been for more than 6 months

2 Yes, I have been, but for legs than 6 months

No, but $I$ intend to in the next 30 days

No, but $I$ intend to in the next 6 months

No, and I do not intend to in the next 6 months

99. Have you tncreased the amount of frutt in your diet?

1 Yes, I have for MORB than 6 months

2 Yes, I have, but for IBSS than 6 months

3 No, but I intend to in the next 30 days

4 No, but I intend to in the next 6 months

5 No, and I do NOT intend to in the next 6 months

100. Have you increased the amount of vegetables in your diet?

1 Yes, I have for MORR than 6 months

2 Yes, I have, but for IRSS than 6 months

3 No, but I intend to in the next 30 davs

4 No, but I intend to in the next 6 months

5 No, and I do NOT intend to in the next 6 months

101. How much control do you feel you have over the amount of frutt and vegetableg in your diet?

1 No control

2 Slight control

3 Hoderate control

4 A lot of control

5 Total control

102. Do you consiatently avold eating hlgh fat foods (french fries, potato chips, hamburgers etc.)?

1 Yes, I have been for more than 6 months

2 Yes, I have been, but for less than 6 months

No, but $I$ intend to in the next 30 dars

No, but $I$ intend to in the next 6 months

5 No, and I do not intend to in the next 6 months

103. Eow much control do you feel you have over the amount of fat in your diet?

1 No control

2 Slight control

3 Moderate control

4 A lot of control

5 Total control

104. What 18 your helght?

feet and inches

105. What 18 your weight?

pounds

STOP HERE. THANK YOU FOR YOUR HELP. 
Continues fram Page 3

IF YOU DO NOT SWOKK CIGARETTES, ANSWER THESB QUESTIONS.

107. How much pressure have you felt from your family, frtends, or othars not to Btart amolktig?

1 No pressure

2 Slight pressure

3 Moderate pressure

4 Extreme pressure

108. Have you thought about trylng clgarate smoking?

1 Yes, but I intend to try amoking in the next 30 days

2 Yes, but I intend to try smoking in the pext 6 months

3 No, I do not intend to try smoking in the next 6 months

THB NEXT OUBSTIONS ARB ABOUT SMOKING.

CIRCLB I IF YOU STRONGLY DISAGRBE WITH THE STATEMISHT.

CIRCIB 5 IF YOU STRONGLY AGREB. IF YOU ARB IN BETWEBN, USB NUMBERS 2, 3, OR 4.

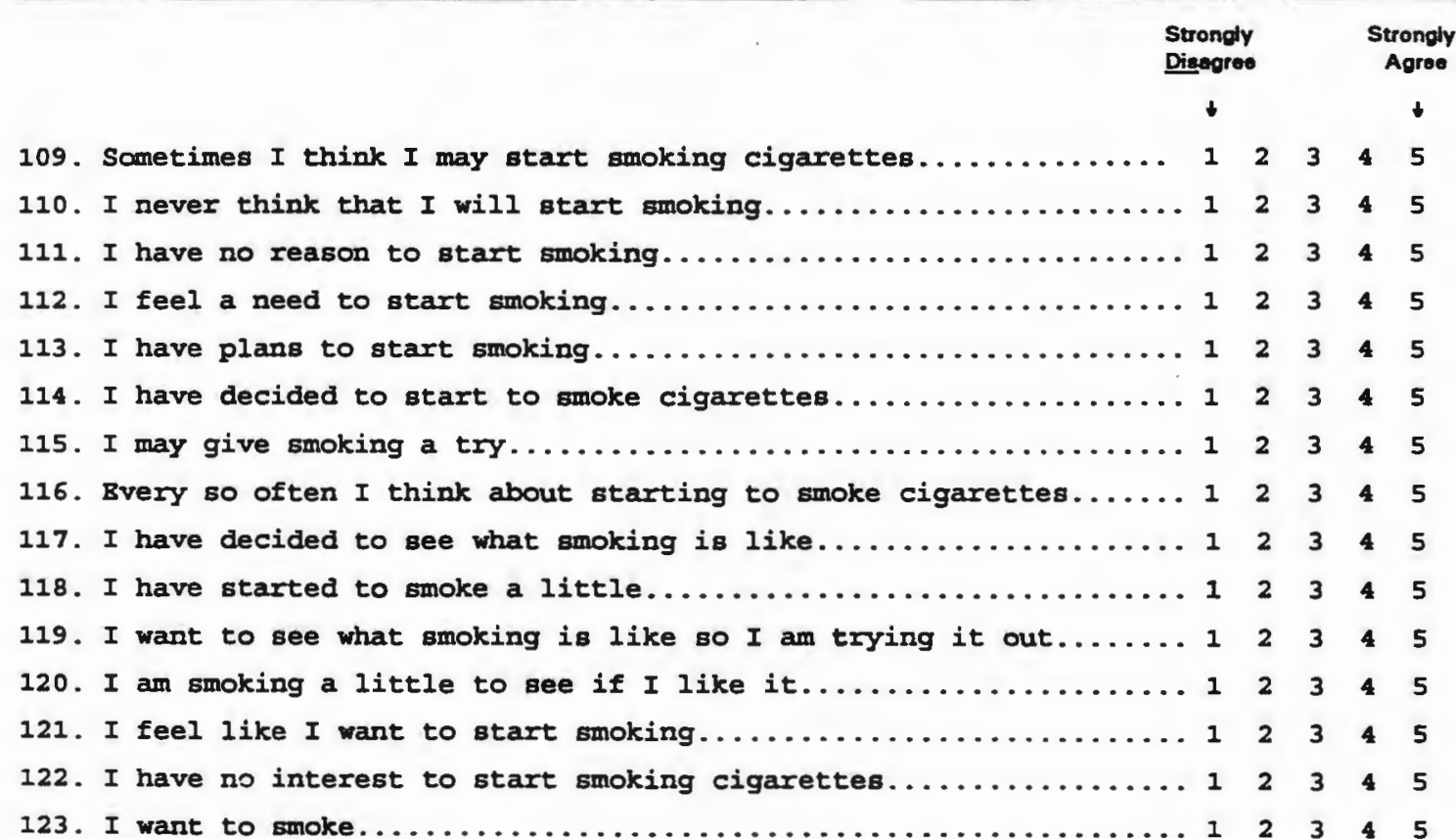

124. Do you think that you may try smoking within the next 6 months?

1 Yes

2 No

125. Do you think that you may try amoking in the next 30 dayg?

1 Yes

2 NO 


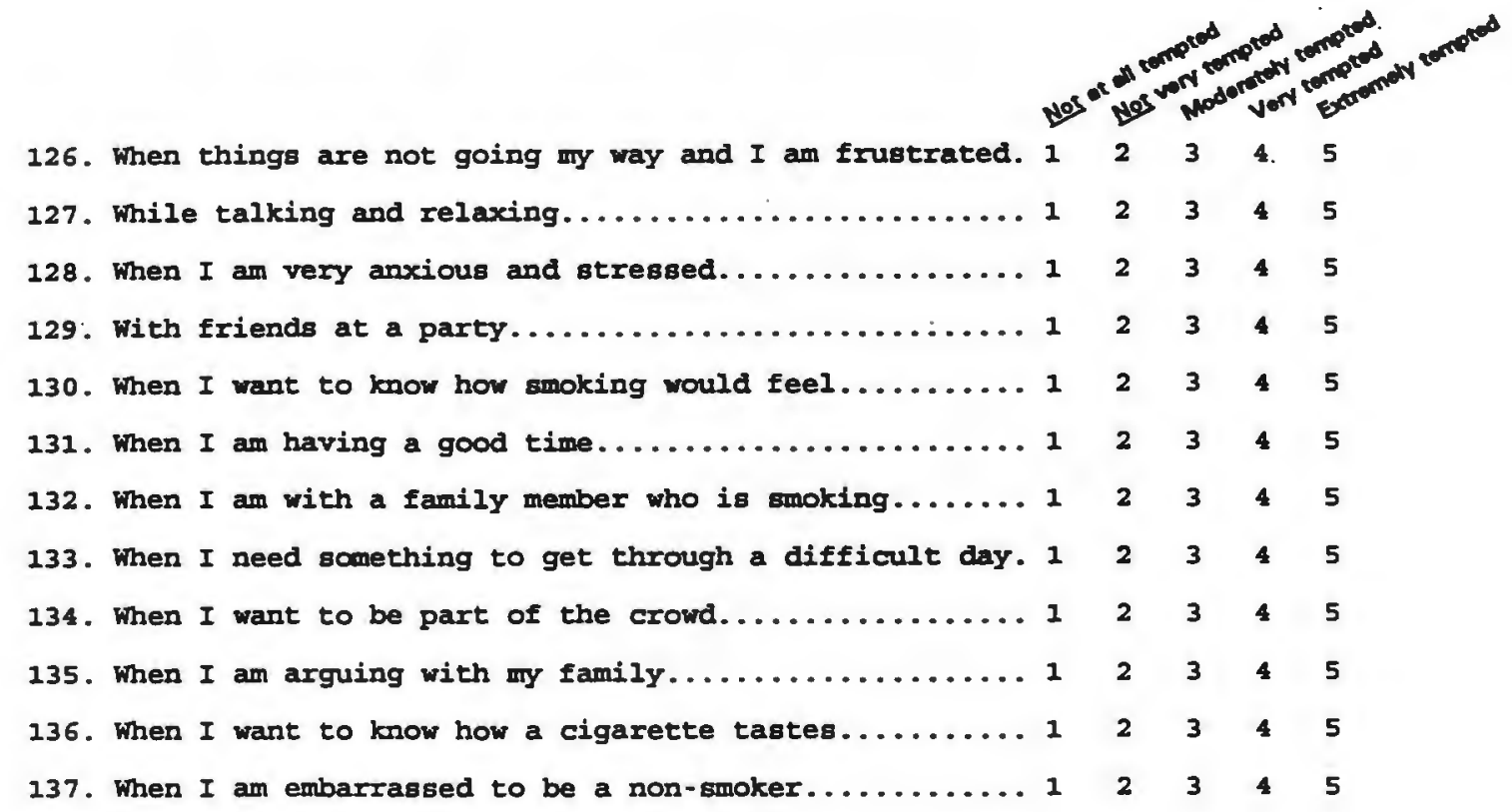

138. Have you ever drank any alcoholtc beverages (such as beer, wine, a wine cooler, or I1quor)?

1 Yeg

2 No

139. In the past 30 days, on how many days did you drink any alcoholle beverages (such as beer, wine, a wine cooler, or l1quor)?

number of days

FOR THB FOLIOWING QUESTIONS ONB DRINK EQUAI TO ONE BEER, A GIASS OF WINE, ONE SHOT (OUNCE) OF HARD LIQUOR, OR ONE WINE COOLER.

140. On days that you drink alcoholic beverages, how many drinks do you usually have? (If you do not arink, write 0. )

drinks 
141. On days that you drink do you usually bave $3^{\circ}$ or more drinks?

1 YES

IF YES, AKSWBR QUBSTIOAS A \& B.

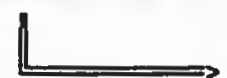

2 No, I usually drink leg日 than 3 drinks

\section{IF NO, ANSWBR QOBSTIONS C\& D}

3 No, I do not drink alcohol

IF NO, ANSWBR QUESTIONS C\&D
A) How long have you been drinking 3 or moro dinks?

1 Less than 3 month

2 Between 3 and 6 months

3 Between 6 moriths and 1 year

4 More than a year

B) Do you pian to cut down to less than 3 drinks?

1 No

2 Yes, in the next 6 months

3 Yes, in the next 30 day

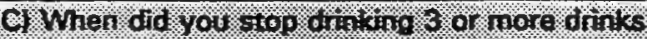
ondays that yov diratik ?

1. Whave never usually dinll, 3 dinks

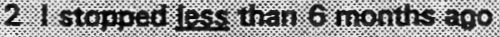

3. / stopped ingere dian 6 montis ago

D) Ba you intend to stat ofinkino 3 or nore dinks on days that rov dink

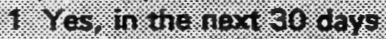

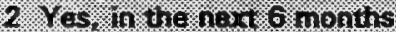

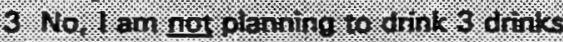

142. Do you drink 6 or more drinks every now and then?

1 YES

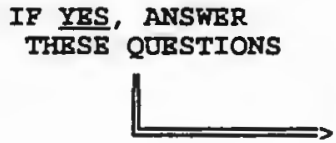

2 NO

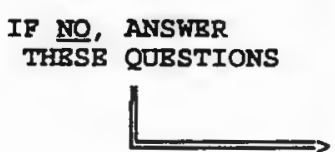

A) How lone have you been drinking 6 or no re drinks every now and then?

1. Less tran 3 montit

2 Between 3 and 6 nontis.

3 Between 6 months and 1 year

4 More than a vear.

B) Do you plan to stop dritiking 6 or more dinks?

1 No

2 Yes, in the next 6 montis

3. Yes, in thia inext:30.days:

d) When did you stop drinking 6 or more difiks?

1. I have never drunk 6 or mor a drinks.

2 Less thin 6 montis ago

3 More 6 months ago

D) Do you intend to drink 6 or more drinks every now and then?

1 Yes, in the next 30 days

2 Yes. in the rext 6 montis.

3 No, / am not panning to drink 6 dinks 
HOW IMPORTANT TO YOU ARE THE FOIIOWING STATEMEINTS IN YOWR DBCISIOS TO DRTNK OR TO NOT DRTINK ALCOHOL.

IF YOD DO NOT DRINK, ARE ANY OF THB FOLWOWING STATEMRNISS REASONS FOR YOO TO NOT DRINK OR REASONS THAT MAKB YOD WANT TO DRIMK

CIRCLR 1 IF IT IS NOT IMPORTANT AT ALL AND 5 IF IT IS EXTREMIELY TMPORTANT. IF YOO ARB IN BETWBEA USB EUMBBRS 2, 3, OR 4.

RATE THB IMPORTANCB TO YOUR DECISIOR TO DRINK OR TO YOUR DRCISION TO FOT DRINK

Not Important ot Al

143. If I buy alcohol then I have less money for other things . . . $1 \quad 2 \quad 3445$

144. Drinking makes me more relaxed and less tense . . . . . . . 1425345

145. Drinking makes me less coordinated . . . . . . . . . . . . . 1424345

146. I do not think as clearly when I drink . . . . . . . . . . . 1 2 3445

147. Alcohol makes my sexual experiences easier and more enjoyable $1 \quad 2 \quad 3 \quad 4 \quad 5$

148. Drinking helps me deal with problems . . . . . . . . . . . . 142345

149. Drinking is bad for my health . . . . . . . . . . . . . . . 1424345

150. Drinking helps give me energy and keep me going . . . . . . $\begin{array}{llllll} & 2 & 3 & 4\end{array}$

151. After drinking I often wake up feeling down . . . . . . . . 142345

152. Without alcohol my life would be more boring and dull •. . $1 \quad 2 \quad 345$

153. I do not do as well at school because of my drinking. . . . $1 \quad 2 \quad 3 \quad 45$

154. I am afraid that if I drink I will become an alcoholic . . . . $1 \quad 2 \quad 3 \quad 4 \quad 5$

155. When I drink I get less angry and less frustrated with others $1 \quad 2 \quad \begin{array}{llll}3 & 4 & 5\end{array}$

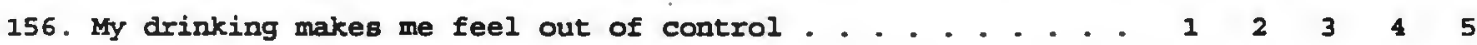

157. Drinking helps me to have fun with friends . . . . . . . . . 1324345

158. Drinking causes problems with others . . . . . . . . . . . . . 1 2 3445

159. I feel less lonely and sad when I drink ............... 1 2 345

160. I seem to argue and fight more if I an drinking. . . . . . . $1 \begin{array}{lllll} & 2 & 3 & 4\end{array}$

161. Drinking makes me more careless . . . . . . . . . . . . . . 132345

162. I do things better when I drink . . . . . . . . . . . . . . . 1 24344

163. I am losing the trust and respect of $m y$ friends and family

because of my drinking . . . . . . . . . . . . . . . . . 1234345

164. I an better at sports after a few drinks of alcohol . . . . . $1 \quad 2 \quad 345$

165. I do not like myself when I drink . . . . . . . . . . . . . . . . 1 2 3 45

166. People seen to like me better when I an drinking . . . . . $1 \quad \begin{array}{lllll}2 & 3 & 4\end{array}$

167. I feel like I'm a slave to alcohol . . . . . . . . . . . . . . 1 2 3445

168. I can talk with people of the opposite sex better

after a few drinks of alcohol . . . . . . . . . . . . . . . . 1224345

169. I am setting a bad example for others with my drinking. . . $\begin{array}{llllll}1 & 2 & 3 & 4 & 5\end{array}$ 
170. I would lose my friends if I did not drink . . . . . . . .

171. Drinking could land me in trouble with the law. . . .....

172. Drinking helps keep my mind off problems.

123

173. Parties are not as much fun if people are drinking alcohol. . 1

174. Drinking helps me think better . . . . . . . . . . . . . . . 1

175. I don't like the way I an when I drink . . . . . . . . . . . . 1

176. Drinking giveg me more courage . . . . . . . . . . . . . . . . 1

177. Beer, wine, and other alcoholic drinks cost too much . . . . 1

178. I feel sexier after a few alcoholic drinks . . . . . . . . . . 1

179. Drinking could get me addicted to alcohol ............ . .

180. Do you ride in a friend's car when the driver has been drinking?

1 Yes, but $I$ intend to stop in the next 30 days

2 Yes, but I intend to stop in the pext 6 months

3 Yes, and I do not intend to stop in the next 6 months

4 No, I stopped in the last 6 months

5 No, I stopped more than 6 months ago

6 No, I have never ridden with Eriends who have been drinking

181. Do you exercise at least 3 times a week for at least 20 minutes each time?

1 Yes, I have been for more than 6 months

2 Yes, I have been, but for less than 6 months

3 No, but I intend to in the next 30 days

4 No, but $I$ intend to in the next 6 months

5 No, and I do not intend to in the next 6 months

182. Do you feel that you axe undex a great deal of stxess?

$$
1 \text { Yes }
$$

2 No

183. Do you consider yourself overwelght?

1 Yes

2 No

184. Have you been trying to loose weight?

1 Yes, I have been for more than 6 months

2 Yes, I have been, but for less than 6 months

3 No, but $I$ intend to in the next 30 days

4 No, but $I$ intend to in the next 6 months

5 No, and I do not intend to in the next 6 monthe

185. Have you increased the amount of frutt in your diet?

1 Yes, I have for MORS than 6 months

Yes, I have, but for IESS than 6 months

No, but $I$ intend to in the next 30 days

No, but $I$ intend to in the next 6 months

No, and I do NOT intend to in the next 6 months

186. Have you Incxeased the amount of regetables in your diet?

Yes, I have for MORB than 6 .months

Yes, I have, but for LESS than 6 montha

No, but $I$ intend to in the next 30 days

No, but $I$ intend to in the next 6 months

No, and I do NOT intend to in the next 6 months 
187. How much control do you feel you have over the amount of frult and vegetables in your diet?

1 No control

2 Slight control

3 Moderate control

4 A lot of control

5 Total control

188. Do you consistently avold aating high fat foods (franch fries, potato chips, hamburgers etc.)?

1 Yes, I have been for more than 6 monthe

2 Yes, I have been, but for lege than 6 months

3 No, but $I$ intend to in the next 30 days

4 No, but I intend to in the next 6 months

5 No, and I do not intend to in the next 6 monthg

189. How much control do you feel you have over the anount of fat in your diet? 1 No control

2 Slight cantrol

3 Moderate control

4 A lot of control

5 Total control

190. What 18 your helght?

feet and inches

191. What $1 \mathrm{~s}$ your walght?

pounds

THANK YOU FOR YOUR HELP. 


\section{Appendix C}

Decisional Balance Short Form 
THE NEXT QUESTIONS ARE ABOUT SMOKING. CIRCLE 1 IF YOU STRONGLY DISAGREE WITH THE STATEMENT. CIRCLE 5 IF YOU STRONGLY AGREE. IF YOU ARE IN BETWEEN, USE NUMBERS 2, 3, OR 4.

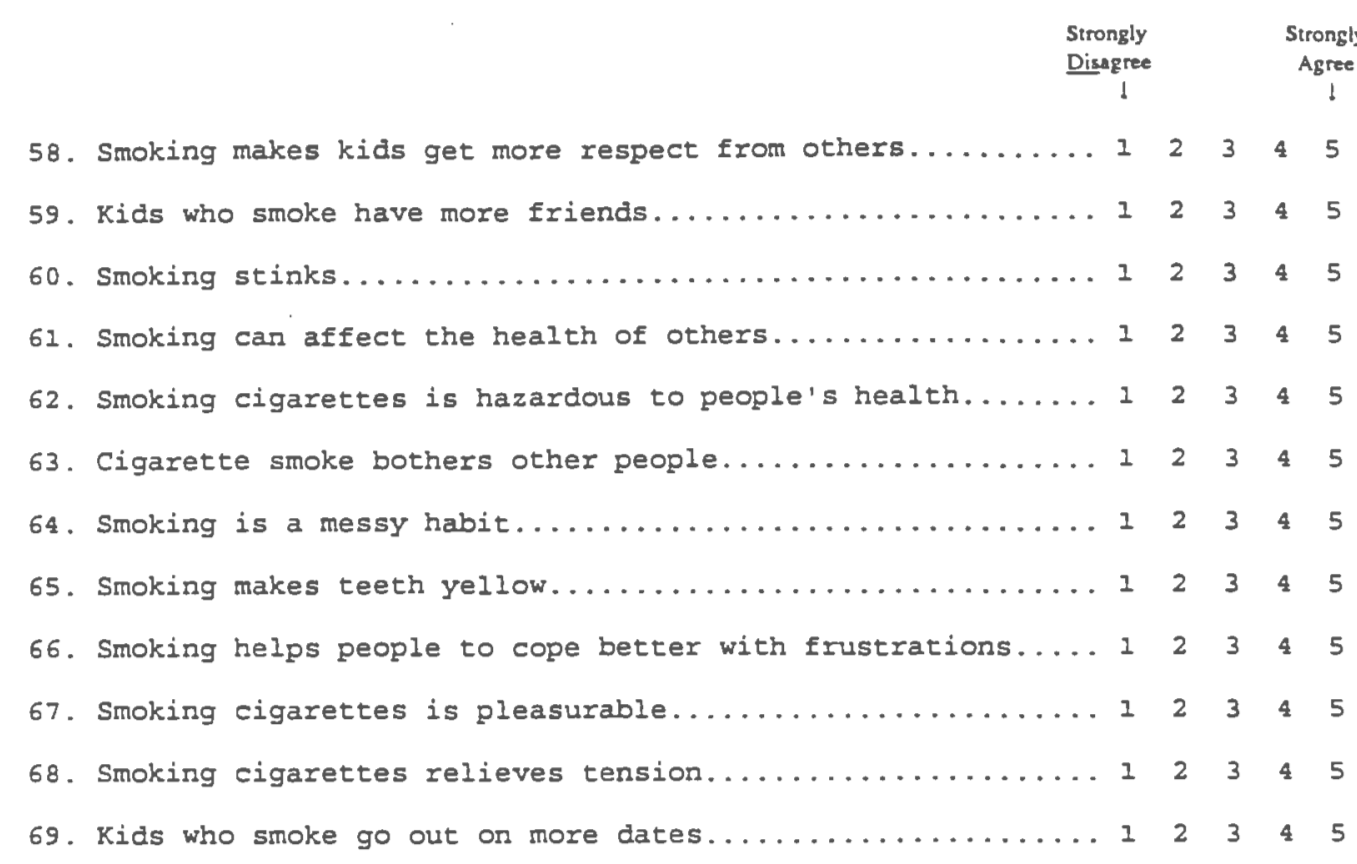


Appendix D

ANOVA Summary Tables 
Table D-1. Summary Table for the Treatment $\times$ Stage of Change $\times$ Time Repeated Measures ANOVA.

\begin{tabular}{lllll}
\hline Source & df & SS & MS & F \\
\hline Between & & & & \\
$\quad$ Stage & 2 & 286.15 & 143.07 & .86 \\
TRT & 1 & 641.19 & 641.19 & $3.84^{*}$ \\
Stage $\times$ TRT & 2 & 902.28 & 451.14 & 2.70 \\
Error & 93 & 15544.65 & 167.15 & \\
& & & & \\
Within & & & & .03 \\
$\quad$ Time & 2 & 1.37 & .69 & .50 \\
Stage $\times$ Time & 4 & 45.12 & 11.28 & 1.20 \\
TRT $\times$ Time & 2 & 54.21 & 27.11 & .45 \\
Stage $\times$ TRT $\times$ Time & 4 & 40.14 & 10.04 & \\
Error & 186 & 4189.53 & 22.52 & \\
\hline Total & & & & \\
p $=.053$ & 296 & 21704.64 & & \\
& & & &
\end{tabular}

Table D-2. Summary Table for the Treatment $x$ Gender $\times$ Time Repeated Measures ANOVA.

\begin{tabular}{lllll}
\hline Source & df & SS & MS & F \\
\hline Between & & & & \\
$\quad$ Gender & 1 & 322.98 & 322.98 & 1.86 \\
TRT & 1 & 824.78 & 824.78 & $4.76^{*}$ \\
Gender x TRT & 1 & 3.36 & 3.36 & .02 \\
$\quad$ Error & 95 & 16464.68 & 173.31 & \\
& & & & \\
Within & & & & \\
$\quad$ Time & 2 & 25.07 & 12.53 & .58 \\
$\quad$ Gender x Time & 2 & 20.75 & 10.38 & .48 \\
$\quad$ TRT x Time & 2 & 104.98 & 52.49 & 2.42 \\
$\quad$ Gender x TRT x Time & 2 & 138.15 & 69.57 & $3.21^{*}$ \\
$\quad$ Error & 190 & 4119.86 & 21.68 & \\
\hline Total & 296 & 22024.61 & & \\
p $<.05$ & & & &
\end{tabular}




\section{BIBLIOGRAPHY}

Allen, L. R. (1986). Measuring attitude toward computer assisted instruction: The development of a semantic differential tool. Computers in Nursing, 4(4), 144-151.

Allen, S.J., \& Hubbard, R. (1984). Regression equations for the latent roots of random data correlation matrices with unities in the diagonal. Multivariate Behavioral Research, 21, 393-398.

Brand, S. (1992). The media lab: Inventing the future at MIT New York: Penguin.

Billings, D. M., \& Cobb, K. L. (1992). Effects of learning style preferences, attitude and GPA on learner achievement using computer assisted interactive videodisc instruction. Journal of Computer-Based Instruction, $\underline{19}(1), 12-16$.

Cattell, R.B. (1966). The Scree test for the number of factors. Multivariate Behavioral Research, 1, 245-276.

Chin, J. P., Diel, V. A., \& Norman, K. L. (1988). 'Development of an instrument measuring user satisfaction with the human-computer interface. Proceedings of SIGGHI'88 (pp. 213-218). New York: ACM/SIGCHI.

Chin, J. P., Norman, K. L., \& Shneiderman, B. (1987). Subjective user evaluation of CF PASCAL programming tools. Technical Report (CAR- 
TR-304). College Park, MD: Human-Computer Interaction Laboratory, Center for Automation Research, University of Maryland.

Coleman, W. D. \& Williges, R. C. (1985). Collecting detailed user evaluations of software interfaces. Proceedings of the Human Factors Society - 29th Annual Meeting (pp. 204-244). Santa Monica, CA.

Cronbach, L.J. (1951). Coefficient alpha and the internal structure of tests.

Psychometrika, 16, 297-334.

Deardorff, W. W. (1986). Computerized health education: A comparison with traditional formats. Health Education Quarterly, 13(1), 61-72.

Devellis, R. F. (1991). Scale development: Theory and applications. Newbury Park, California: SAGE publications.

Kaiser, H.F. (1958). The varimax criterion for analytic rotation in factor analysis. Psychometrika, 23, 187-200.

Kulik, C. C., \& Kulik, J. A. (1991). Effectiveness of computer based instruction: An updated analysis. Computers in Human Behavior, 7, 75-94.

McConnaughy, E., DiClemente, C. C., Prochaska, J. O., \& Velicer, W. F. (1989). Stages of change in psychotherapy: A follow up report. Psychotherapy, $\underline{26}$ 494-503.

McConnaughy, E., Prochaska, J. O., \& Velicer, W. F. (1983). Stages of change in psychotherapy: Measurement and sample profiles. Psychotherapy: Theory, Research and Practice, 20, 368-375. 
Nunnally, J. C. (1978). Psychometric theory (2nd. ed.). New York: McGraw-Hill Book Company.

Prochaska, J. O., \& DiClemente, C. C. (1984). The transtheoretical approach: Crossing traditional boundaries of therapy. Howewood, IL: Dow Joune. Irwin.

Shneiderman, B. (1992). Designing the User Interface: Strategies for effective human - computer interaction. Reading, MA: Addison-Wesley.

Steinberg, E. R. (1991). Computer-assisted instruction: A synthesis of theory, practice, and technology. Hillsdale, New Jersey: Lawrence Erlbaum Associates.

USDHHS. (1988). Surgeon General's report on smoking and health. Department of Health and Human Services, Washington, DC: US Government Printing Office.

USDHHS. (1990). Smoking and health: A national status report.

Department of Health and Human Services, Washington, DC: US Government Printing Office.

Velicer, W.F. (1976). Prediction and association for $\mathrm{N}$-way classification tables. Evaluation Reviews, $\underline{6}$, 247-266.

Velicer, W. F., Prochaska, J. O., Bellis, J. M., DiClemente, C. C., Rossi, J. S., Fava, J. L., \& Steiger, J. H. (1993). An expert system intervention for smoking cessation. Addictive Behaviors, 18, 269-290. 
Velicer, W. F., DiClemente, C. C., Prochaska, J. O., Brandenburg, N. (1985). Decisional balance measure for assessing and predicting smoking status. Journal of Personality and Social Psychology, 48(5), 1279-1289.

Wallace, D. F., Norman, K. L., \& Plaisant, C. (1988). The american voice and robotics "guardian" system: A case study in user interface usability evaluation. Technical Report (CAR-TR-392). College Park, MD: HumanComputer Interaction Laboratory, Center for Automation Research, University of Maryland.

Weisberg, M. (1992, November). Guidelines for designing effective and healthy learning environments for interactive technologies. Paper presented at the Association for the Development of Computer-Based Instructional Systems, 34th International Conference, Norfolk, VA. 